\title{
LAS CAUSAS DE CONEXIÓN PENAL Y SU APLICACIÓN TRAS LA REFORMA OPERADA POR LA LEY 41/2015*
}

\section{The causes of criminal connection and their application after the reform operated by the Law 41/2015}

\author{
Ignacio José Cubillo López \\ Profesor Titular de Derecho Procesal \\ Universidad de Córdoba \\ dc1cubli@uco.es
}

doi: http://dx.doi.org/10.18543/ed-65(2)-2017pp39-83

Recibido: 29.09.2017

Aceptado: 28.11.2017

\section{Resumen}

En este trabajo se estudian las causas de conexión delictiva del artículo 17 de la Ley de Enjuiciamiento Criminal y la aplicación que los tribunales pueden hacer de esta norma. Este precepto ha sido reformado en 2015 en un doble sentido: de una parte, se amplían los motivos por los que cabe considerar conexos dos o más delitos; y de otra parte, se incrementan las facultades de valoración del juzgador a la hora de apreciar si resulta necesaria o conveniente la acumulación de causas por delitos conexos. En este artículo se analizan ambas cuestiones, tanto el alcance de la apreciación que corresponde al juez para decidir entre el enjuiciamiento conjunto o separado de infracciones conexas, como el contenido y los límites de las distintas causas de

* Cómo citar / Citation 'Chicago-Deusto' (Autor-fecha / Author-date / Lista de referencias / Reference list entries): Cubillo López, Ignacio José. 2017. «Las causas de conexión penal y su aplicación tras la reforma operada por la Ley 41/2015». Estudios de Deusto 65, n. ${ }^{\circ}$ 2: 00-00. doi: http://dx.doi.org/10.18543/ed-65(2)-2017pp39-83. 
conexión -las antiguas que permanecen y las nuevas que se introducen-a la luz de la jurisprudencia.

\section{Palabras clave}

Conexión penal; Concurso de delitos; Acumulación procesal.

\section{Abstract}

This paper examines the causes of criminal connection of article 17 of the Law on Criminal Procedure and the application that the courts can make of this rule. This precept has been reformed in 2015 in two ways: on the one hand, the reasons why two or more offenses can be considered connected are broadened; and on the other hand, the judge's assessment powers increase when it comes to assessing whether the accumulation of cases for related offenses is necessary or convenient. This article examines both issues, both the scope of the judge's assessment to decide between the joint or separate prosecution of related offenses, and the content and limits of the different causes of connection -the old ones that remain and the new ones which are introduced- in the light of the case-law.

\section{Keywords}

Criminal connection; Contest of crimes; Procedural Accumulation. 


\begin{abstract}
Sumario: I. De LA NECESIDAD A LA CONVENIENCIA DEL ENJUICIAMIENTO CONJUNTO DE LOS DELITOS CONEXOS. 1. Objeto principal de la reforma de 2015 en materia de conexión delictiva. 2. Razones para acumular o no el enjuiciamiento de delitos conexos. 3. El precedente del procedimiento abreviado y de la jurisprudencia anterior a la reforma. 4. Primeras resoluciones posteriores a la reforma y alcance de la valoración que corresponde al Tribunal sobre la acumulación. II. LOS NEXOS DE CONEXIÓN TRAS LA REFORMA. 1. Nexos de conexión que se mantienen: las llamadas conexión subjetiva y conexión objetiva. 1.1. La llamada conexión subjetiva. 1.2. La llamada conexión objetiva o instrumental. 2. Los nuevos nexos de conexión. 2.1. Los delitos de favorecimiento real y personal y el blanqueo de capitales respecto del delito antecedente. 2.2. Los delitos de lesiones o daños recíprocos. III. CONCLUSIONES. BiBliografÍA.
\end{abstract}

\title{
I. DE LA NECESIDAD A LA CONVENIENCIA DEL ENJUICIAMIENTO CONJUNTO DE LOS DELITOS CONEXOS
}

\section{Objeto principal de la reforma de 2015 en materia de conexión delictiva}

La última reforma de la Ley de Enjuiciamiento Criminal (en adelante LECr) ha sido la operada por la Ley 41/2015, de 5 de octubre, de modificación de la Ley de Enjuiciamiento Criminal para la agilización de la justicia penal y el fortalecimiento de las garantías procesales. Como puede apreciarse por su denominación, esta ley tiene dos finalidades principales y una de ellas es agilizar los procesos penales, introduciendo o modificando disposiciones que sin lesionar los derechos de las partes conduzcan a un proceso más rápido y eficaz. Así, la primera modificación legal que se prevé con este fin es la de «las reglas de conexidad y su aplicación al determinar la competencia de los tribunales», según la Exposición de Motivos de la Ley. El objeto de este trabajo consiste en estudiar el alcance de la reforma en esta concreta materia.

Con relación a la modificación de la conexión, señala el Preámbulo de la misma Ley:

«La reforma de las reglas de conexidad supone una racionalización de los criterios de conformación del objeto del proceso, con el fin de que tengan el contenido más adecuado para su rápida y eficaz sustanciación. Con ello se pretende evitar el automatismo en la acumulación de causas y la elefantiasis procesal que se pone de manifiesto en los denominados macroprocesos. La acumulación por conexión solo tiene sentido si concurren ciertas circunstancias tasadas que se expresan en el artículo 17.1 y 2 de la Ley de Enjuiciamiento Criminal, cuando el conocimiento de los asuntos 
por separado no resulte más aconsejable. Esta valoración de la concurrencia de las reglas y condiciones de conexidad corresponde en exclusiva al juez instructor».

A la vista de este texto, cabe afirmar desde ya que el principal punto de reforma de las normas de conexión ha sido evitar la aplicación automática de los criterios legales que permiten entender que dos o más delitos son conexos $\mathrm{y}$, consecuentemente, deben ser instruidos y enjuiciados en un mismo proceso.

Así, la versión originaria de la LECr disponía en su art. 300 lo siguiente: "Cada delito de que conozca la Autoridad judicial será objeto de un sumario. Los delitos conexos se comprenderán, sin embargo, en un solo proceso». Por tanto, este breve y centenario precepto establecía una regla y una excepción. La regla general sería que cada delito, o mejor: cada hecho o conjunto de hechos susceptibles de ser calificados con individualidad delictiva, integraría el objeto de un proceso; y como excepción, cuando existan varios hechos calificables de delitos conexos según la propia ley, el proceso no tendría un objeto simple sino plural, comprensivo de los diferentes hechos constitutivos de distintas infracciones penales. El problema es que esta excepción parecía imponerse de manera necesaria, en atención a la forma verbal imperativa «comprenderán», la cual daba a entender que, siempre que se estuviese en presencia de hechos punibles que la ley considerase como delitos conexos, su enjuiciamiento debería ser conjunto. Y la ley establecía qué delitos tenían conexión entre sí en el art. 17, con sus cinco ordinales ${ }^{1}$.

¿Qué hace, entonces, la reforma de que tratamos? En primer lugar, suprime el citado art. $300 \mathrm{LECr}$, y su contenido, modificado, pasa a integrar el art. 17.1 LECr; de manera que en esta norma se mantiene la regla general recién mencionada: "Cada delito dará lugar a la formación de una causa», pero a la vez se altera la excepción a dicha regla, por cuanto para que proceda

\footnotetext{
${ }^{1}$ A fin de facilitar su consulta, recogemos aquí el art. 17 LECr en su versión anterior a la reforma de 2015: «Considéranse delitos conexos:

1. ${ }^{\circ}$ Los cometidos simultáneamente por dos o más personas reunidas, siempre que éstas vengan sujetas a diversos Jueces o Tribunales ordinarios o especiales, o que puedan estarlo por la índole del delito.

2. ${ }^{\circ}$ Los cometidos por dos o más personas en distintos lugares o tiempos si hubiera precedido concierto para ello.

3. ${ }^{\circ}$ Los cometidos como medio para perpetrar otros, o facilitar su ejecución.

4. ${ }^{\circ}$ Los cometidos para procurar la impunidad de otros delitos.

$5 .^{\circ}$ Los diversos delitos que se imputen a una persona al incoarse contra la misma causa por cualquiera de ellos, si tuvieren analogía o relación entre sí, a juicio del Tribunal, y no hubiesen sido hasta entonces sentenciados».
} 
el enjuiciamiento conjunto de varios delitos, no sólo será preciso estar ante hechos que revistan la apariencia de delitos conexos, sino que además se requiere que el órgano judicial aprecie que «la investigación y la prueba en conjunto de los hechos resulten convenientes para su esclarecimiento y para la determinación de las responsabilidades procedentes», en cuyo caso accederá a la acumulación de objetos procesales conexos, «salvo que suponga excesiva complejidad o dilación para el proceso».

Dicho con otros términos: junto al elemento que podemos calificar de objetivo, consistente en la concurrencia de un vínculo legal de conexión entre los hechos punibles que se instruyen o enjuician, y que ya se exigía con la regulación anterior, ahora se requiere también un elemento de carácter subjetivo o valorativo, que igualmente debe estar presente para que el juez pueda acordar la sustanciación en un solo proceso de los distintos hechos ligados por un vínculo de conexión. El elenco de nexos objetivos de conexión se amplía -respecto del anterior art. $17 \mathrm{LECr}-\mathrm{y}$ se recoge en el apartado 2 del nuevo art. 17 LECr, como tendremos ocasión de examinar. Y las circunstancias que el órgano judicial ha de valorar para adoptar la acumulación se disponen, como se acaba de indicar, en el apartado 1 del mismo precepto.

Nótese que la valoración judicial que se exige para poder acumular dos objetos procesales conexos presenta una doble vertiente, positiva y negativa. De un lado, debe apreciarse la concurrencia positiva de razones de conveniencia del enjuiciamiento conjunto, que lleven a pensar que unificar la investigación y el juicio sobre hechos que de algún modo se encuentran ligados va ayudar más a su fijación como ciertos y a su calificación penal que el hacerlo por separado. De otro lado, se debe valorar si acudir a tal acumulación procesal no tendrá como consecuencia negativa que el proceso se complique o se ralentice de manera excesiva; no vaya a ser que aquello que se adopta con un fin de agilizar las actuaciones se convierta en motivo de dilaciones mayores.

Para valorar si la acumulación ocasionará esas posibles consecuencias negativas, de un lado, debe atenderse a que no provoque una complicación excesiva del proceso que pasará a tener un objeto plural, lo cual habrá que examinar caso a caso, sin que existan parámetros legales para hacerlo². De otro lado, se analizará que el enjuiciamiento conjunto no conlleve un retraso o dilación excesiva, y aquí la misma reforma sí proporciona un elemento de

${ }^{2}$ Como señala Muerza: «no es algo que se pueda determinar con base en una reglas generales sino que dependerá de muchos elementos, como son: la naturaleza de los delitos, la dificultad de la instrucción, los medios materiales y humanos existentes en ese Juzgado concreto... En fin, de muchos factores que si hacen al proceso "excesivamente" complejo debe llevar al órgano jurisdiccional a su enjuiciamiento separado», en Muerza Esparza, Las reformas procesales penales de 2015 (Cizur Menor: Aranzadi, 2015), 54. 
comparación, ya que, como es sabido, introduce unos plazos máximos para efectuar la instrucción en el nuevo art. 324 LECr. «Por tanto, si tenemos en cuenta esos plazos, el órgano jurisdiccional deberá ponderar si la tramitación en un solo proceso de los delitos conexos se va a prolongar o no por encima de aquellos para acordar la acumulación $»^{3}$.

En consecuencia, puede afirmarse que la nueva regulación ha supuesto un cambio o paso de la necesidad a la conveniencia del enjuiciamiento conjunto de los delitos conexos. Ya no será necesario acumular -en todo caso- el enjuiciamiento de dos o más hechos punibles cuando presenten nexos de conexión, sino que habrá que valorar -caso a caso- si existen razones positivas por las que conviene hacerlo o razones negativas por las que conviene evitarlo. De este modo, cobra un peso mayor el elemento valorativo que corresponde al juzgador ${ }^{4}$.

\section{Razones para acumular o no el enjuiciamiento de delitos conexos}

Ha de advertirse que, pese a la redacción del ahora derogado art. 300 LECr, hace más de cuatro décadas De la Oliva ${ }^{5}$ puso de manifiesto que la excepción a la regla, contenida en la segunda prescripción de dicho precepto -Los delitos conexos se comprenderán, sin embargo, en un solo proceso-, no podía entenderse como imperativa, y que el tribunal había de ponderar en cada caso si debía aplicarse o no esta previsión legal. Esta ponderación se haría teniendo en cuenta los fines a los que sirve el enjuiciamiento conjunto de delitos conexos, de manera que, si en el caso concreto la acumulación conlleva los objetivos que se esperan, debería acordarse; pero si dicha acumulación no sirve para lo que se pretende con ella, o incluso tiene como resultado lo contrario de lo que se busca, el juez habría de decretar el enjuiciamiento separado de delitos que presentan nexos de conexión. Lo anterior obliga a

${ }^{3}$ Muerza, Las reformas..., 54.

${ }^{4}$ Con similares términos, Aguilera expresa que: «la acumulación de procesos ya no se concibe como algo automático, sino como una posibilidad en principio condicionada a la apreciación de una circunstancia positiva (que el enjuiciamiento conjunto de los hechos resulte conveniente para su esclarecimiento y la determinación de las responsabilidades procedentes) y a otra negativa (que el enjuiciamiento conjunto no suponga excesiva complejidad o dilación para el proceso). La acumulación pasa, pues, a dibujarse en términos de conveniencia, de libre apreciación subjetiva», en Marien Aguilera Morales, «La agilización de la justicia penal en el proyecto de reforma de la Ley de Enjuiciamiento Criminal (O «de cuando el oro parece»), Diario La Ley, no 8551 (2015): 5.

5 Andrés De la Oliva Santos, La conexión en el proceso penal (Pamplona: EUNSA, 1972), 74-84. Las ideas que se exponen a continuación se apoyan en esta fuente. Esta monografía del Prof. De la Oliva fue la primera -y sigue siendo casi la única- sobre la materia, y constituye la base sobre la que se asienta el presente trabajo. 
indagar en las razones de por qué la ley establece que los hechos punibles que pueden calificarse de conexos deberían ser objeto de un solo proceso.

El autor citado realiza un estudio del origen y el desarrollo históricos de lo que suele ofrecerse como respuesta clásica a la cuestión formulada, de por qué han de enjuiciarse a la vez los delitos conexos, que no es otra que la máxima latina: continentia causae dividi non debet. Y sucede que esta máxima «arguye una idea apriorística sobre el objeto del proceso y resulta ser una condensación de aquellos casos en que se intuye la necesidad o la conveniencia de hacer entrar en una única causa diversos objetos o materias»; pero realmente no nos ofrece una explicación de por qué la continencia de una causa criminal debe comprender los delitos conexos, por lo que se quedará en una petición de principios, si no se exploran las razones que están detrás de tal regla o los objetivos a los que responde . $^{6}$

El mismo autor señala que las razones que suelen ofrecerse para justificar la acumulación procesal de objetos penales suelen ser de dos tipos: unas, relacionadas con la seguridad jurídica, como es el fin de evitar sentencias contradictorias; y las otras razones están ligadas con la economía procesal, o el ahorro y simplificación de las actuaciones.

En cuanto al primer grupo de motivos, De la Oliva cuestiona que tal acumulación sirva realmente para evitar decisiones o fallos contradictorios, al ir referida a delitos que siempre son distintos: «si se trata de delitos distintos -y la pluralidad de delitos es presupuesto esencial de la conexión- no parece que, en rigor, quepa hablar de decisiones contradictorias, pues lo más grave que podría suceder siguiéndose un proceso distinto por cada delito, sería que se apreciara de distinta manera por cada juzgador el elemento de parcial coincidencia que fundaría la conexión y este elemento no tiene relevancia en la decisión propiamente dicha» ${ }^{7}$.

El autor desarrolla con detalle esta afirmación, con referencia a los diferentes supuestos que fundan la conexión. Por ejemplo, sobre el primero de ellos (recogido en el antiguo art. $17.1^{\circ} \mathrm{y}$ en el actual -aunque modificado, como veremos- art. $17.2 .1^{\circ}$, ambos LECr), relativo a la simultaneidad de delitos cometidos por personas distintas en un mismo lugar, si estos delitos se enjuician por separado no tiene por qué haber contradicción entre el fallo del delito cometido por A y el del delito cometido por B, aunque en un caso el fallo sea absolutorio y en otro condenatorio, por cuanto se trata -insistimos- de delitos diferentes. Si acaso puede que un fallo se pronuncie y el otro no, o lo hagan los dos de forma contradictoria, sobre el

${ }^{6}$ De la Oliva, La conexión..., 77. El estudio sobre el significado e historia del brocardo latino se encuentra en las páginas $74-77$, y las razones que tal máxima encierra se analizan en las páginas 77-84.

7 De la Oliva, La conexión..., 78. 
elemento de la reunión de las dos personas en un mismo lugar y tiempo, pero este elemento «no tiene relevancia alguna para calificar y penar, en su caso, los hechos distintos cometidos por $\mathrm{A}$ y $\mathrm{B} »{ }^{8}$.

$\mathrm{Y}$ algo similar sucede en el supuesto del antiguo art. $17.2^{\circ}$ (y nuevo art. 17.2.2 $2^{\circ}$ LECr, referente a delitos cometidos por personas distintas en diferentes lugares y tiempos pero con concierto para delinquir; aquí, podría haber contradicción en la apreciación del elemento «concierto», si los delitos se juzgan en procesos distintos, lo que podría ser relevante de cara a estimar que exista la agravante de premeditación, pero sólo sucedería esto y «seguiría sin poder hablarse en rigor de decisiones contradictorias: habría tan sólo criterios dispares en los distintos órganos jurisdiccionales al enjuiciar -si ello fuera posible- un aspecto coincidente en hechos distintos» ${ }^{9}$.

En cambio, sí puede suceder que el enjuiciamiento separado de delitos conexos impida la aplicación de ciertas normas de determinación -y limitación- de la pena, como la del art. 77.3 CP con relación a los delitos en los que uno es medio para perpetrar el otro, motivo de conexión previsto en el antiguo art. 17.3 (y nuevo art. 17.2.3 ${ }^{\circ}$ ) LECr; o la regla del art. 76.2 CP con relación a los diversos delitos atribuibles a un mismo sujeto y que guardan relación o analogía entre sí, los cuales se consideraban conexos según el antiguo art. $17.5^{\circ} \mathrm{LECr}$ (y, aunque han perdido tal consideración, podrán sustanciarse de forma conjunta, de conformidad con el nuevo art. 17.3 LECr). Pero en estos casos, el peligro del enjuiciamiento separado no será, nuevamente, que se dicten fallos contradictorios, sino la inaplicación de una norma de penalidad. Evitar esta inaplicación, o más bien: favorecer la aplicación de dichas normas penales, puede ser un objetivo loable y atendible del enjuiciamiento conjunto de diversos delitos; pero no se confunda con el de evitar sentencias contradictorias ${ }^{10}$.

El otro tipo de razones principales que justifican la acumulación tiene que ver con la economía procesal, pues parece claro que unificar en un solo proceso la instrucción y el enjuiciamiento de diversos delitos conexos conlleva «una lógica y obligada racionalización de la actividad jurisdiccional» ${ }^{11}$, y supone un ahorro evidente de tiempo y de energías procesales.

Junto a los motivos anteriores, pueden añadirse otros, de no menor importancia. Como que, al enjuiciar a la vez varios delitos relacionados entre sí, de

8 De la Oliva, La conexión..., 79.

9 De la Oliva, La conexión..., 79-80.

${ }^{10}$ De la Oliva, La conexión..., 80, 81 y 83. Las ideas expuestas se apuntan en estas páginas, aunque con referencia a los preceptos penales equivalentes que estaban en vigor en aquel momento.

11 De la Oliva, La conexión..., 81. 
algún modo puede facilitarse el descubrimiento de la verdad material ${ }^{12}$, pues la investigación se proyecta en conjunto sobre hechos que, pese a ser diversos y determinar una distinta calificación penal, históricamente se han producido con un cierto grado de unidad o de ligazón.

Además, puede presentarse como especialmente conveniente «que sean objeto de un único proceso aquellos complejos histórico-fácticos respecto de los cuales sea imposible o muy difícil determinar, prima facie, de qué lado de la frontera entre la unidad y la pluralidad delictiva se encuentran ${ }^{13}$. En efecto, a veces no es fácil saber al comienzo del proceso si unos sucedidos con apariencia delictiva constituyen varios delitos diferentes, o tan solo un delito que ha sido cometido por varias personas, o en el que confluye una agravante, o si se trata de un delito complejo o de un delito continuado, etc. Por eso, en estas situaciones, puede ser muy útil que el proceso verse sobre todo ese conjunto de hechos, aunque después se determine que existió una pluralidad de delitos, a fin de que pueda acertarse precisamente en la calificación jurídico-penal de esos hechos y en la consecuente penalidad de los mismos ${ }^{14}$.

La consecuencia de todo lo anterior es que hay casos en los que conviene acumular en un proceso el enjuiciamiento de varios hechos punibles, porque así se alcanzarán los objetivos que se han apuntado, y otros casos en los que, por el contrario, no será necesaria ni conveniente dicha acumulación. Por ello, el autor citado preconizaba que la norma que establecía que «Los delitos conexos se comprenderán ... en un solo proceso» no podía ser imperativa, sino que había de quedar a la ponderación del juzgador en el caso concreto. Y concluía que no sería precisa dicha acumulación en los siguientes casos: «En aquellos en que del enjuiciamiento conjunto no dependan cuestiones de calificación jurídica fundamentales o decisiones sobre penalidad de trascendencia indudable, atendiendo siempre al criterio de racionalización de las actuaciones jurisdiccionales, a su rapidez y a la economía procesal» ${ }^{15}$.

Nótese el parecido de tales conclusiones -escritas en 1972- con el examen que el nuevo art. 17.1 LECr exige ahora al juzgador para que pueda sustanciar en un solo proceso varios delitos calificables de conexos, sobre si concurren las circunstancias positiva y negativa antes referidas, esto es: que convenga para esclarecer los hechos y determinar la pena, y que no complique o retrase excesivamente las actuaciones.

12 De la Oliva, La conexión..., 82.

13 De la Oliva, La conexión..., 82.

${ }^{14}$ De la Oliva, La conexión ..., 82-83.

15 De la Oliva, La conexión..., 83-84. 


\section{El precedente del procedimiento abreviado y de la jurisprudencia anterior a la reforma}

La opinión recién expuesta -sobre que el juzgador podrá valorar si conviene o no la acumulación de delitos conexos, por no ser ésta necesaria sino sujeta a razones de conveniencia- no se quedó sólo en el terreno doctrinal, sino que tuvo su reflejo legal, cuando se incorporó a la LECr el Título con las normas del procedimiento abreviado, lo que sucedió mediante la Ley Orgánica 7/1988, de 28 de diciembre. Entre los preceptos de este Título legal (antiguos arts. 779-798), se dispuso, en el art. 784.7 ${ }^{\mathrm{a}}$, que: «Para enjuiciar los delitos conexos comprendidos en este Título, cuando existan elementos para hacerlo con independencia, y para juzgar a cada uno de los imputados, cuando sean varios, podrá acordar el Juez la formación de las piezas separadas que resulten convenientes para simplificar y activar el procedimiento». Esta norma se mantuvo en vigor tras la profunda reforma del procedimiento abreviado operada por la Ley 38/2002, de 24 de octubre, pasando a situarse en la regla $6^{\mathrm{a}}$ del art. 762 LECr; y esta regla sólo ha sido modificada por la Ley 41/2015 en que ahora se habla de «encausados» cuando antes se decía «imputados».

Por tanto, aunque fuese de manera limitada a los delitos enjuiciados a través del procedimiento abreviado, existía una base legal, previa a la reforma actual, para que el órgano judicial pudiese valorar la conveniencia o no de separar la tramitación procesal de varios delitos que apareciesen como conexos. Como puede leerse en la norma citada, la conveniencia de separar se mediría en razón de si ello supone una «simplificación» y «activación» de las actuaciones, es decir, en razones de economía procesal; y se acordaría cuando existiesen elementos para juzgar cada delito con independencia, lo que no es muy claro qué significa, pero podemos entender que se refiere a que los distintos hechos punibles pudieran calificarse correctamente de forma autónoma, o si se quiere: con seguridad jurídica ( $\sin$ incurrir en contradicciones o, en términos clásicos, sin romper la continencia de la causa).

Con apoyo en esa base legal se fue generando una jurisprudencia cada vez más favorable a cuestionar el presunto carácter imperativo del entonces todavía vigente art. $300 \mathrm{LECr}$, en la que se hablaba del llamado «principio de indivisibilidad» de los procedimientos, siendo la acumulación de delitos conexos una manifestación de esta indivisibilidad. En esta jurisprudencia se precisaba que: así como cuando el proceso versa sobre un solo hecho punible -con distintos elementos- la indivisibilidad del procedimiento es del todo necesaria, no sucede lo mismo cuando existen distintos hechos punibles que resulten conexos, pues aquí, en función de cuál sea el tipo de nexo entre ellos, la unidad de procedimiento puede ser necesaria o solo conveniente. La necesidad o conveniencia de la conexión se cifrará en razones ligadas al acierto en el enjuiciamiento o a la economía procesal; y estas razones las tendrá que valorar el 
juzgador en el caso concreto, para decidir si acumula o separa las causas. Como ejemplo de la vigencia de esta «conexión de conveniencia» está la norma del procedimiento abreviado, recién referida. Y todo ello abunda, concluye la misma jurisprudencia, en el carácter no imperativo de la segunda prescripción del viejo art. 300 LECr. Pensamos que la sentencia básica en la que se expone esta doctrina jurisprudencial es la Sentencia del Tribunal Supremo -en adelante STS- de 5 de marzo de 1993 (RJ 1994\700), en la que se afirma:

«La conexión es, prima facie, una aplicación del principio de indivisibilidad de los procedimientos, pero no implica (a diferencia de cuando se trata de un hecho único) la necesariedad de esa indivisibilidad. La indivisibilidad obliga a reunir en el enjuiciamiento todos los elementos de un mismo hecho de forma que responda aquélla a la existencia de una única pretensión punitiva cuya resolución no puede fraccionarse. La conexidad, por el contrario, agrupa hechos distintos (al menos desde el punto de vista normativo, al ser susceptibles de calificación separada) que por tener entre sí un nexo común, es aconsejable se persigan en un proceso único por razones de eficacia del enjuiciamiento y de economía procesal. Ese nexo puede resultar de la unidad de responsables, de una relación de temporalidad (simultaneidad en la comisión) o de un enlace objetivo de los hechos. Pero la fuerza unificadora del nexo, no es la misma en todos los casos, especialmente en el de coetaneidad de la ejecución, en el que la simple coincidencia temporal de delitos individualizados y diferentes, puede permitir su enjuiciamiento en causas separadas, mientras no lo permite, en cambio, la comisión conjunta por varios partícipes, obrando de acuerdo, de unos mismos hechos simultáneos. Esta distinción entre conexidad necesaria y conexidad por razones de conveniencia o economía procesal, aparece reconocida en la actual regla $7^{\text {a }}$ del art. 784 LECr... con lo que viene a reconocer que hay casos en los que la regla del enjuiciamiento conjunto de los delitos conexos no es una regla imperativa y de orden público y hasta debe ceder ante razones de simplificación o rapidez del proceso».

Esta sentencia es seguida y citada por otras resoluciones posteriores, en las que se recoge la misma doctrina. Como ejemplo, el Auto del Tribunal Superior de Justicia -en adelante TSJ- de la Comunidad Valenciana de 4 de julio de 2011 (ARP\2011\1145); en él se rechaza la acumulación pretendida de un procedimiento abreviado por diversos hechos punibles (relativos a la presunta financiación irregular del Partido Popular, en el conocido como caso Gürtel), con un procedimiento ante el Tribunal del Jurado, por un delito de cohecho pasivo impropio (por aceptar prendas de vestir como regalo). Y se rechaza la acumulación de los dos procedimientos por distintos motivos, pero entre ellos por la doctrina recién expuesta - de la «conexión de conveniencia»-, concluyendo al respecto que: «se viene a permitir el enjuiciamiento separado aun existiendo conexidad, con lo que se entiende que viene a reconocerse que existen supuestos en los que la regla del enjuiciamiento 
conjunto de los delitos conexos (art. 300 LECrim), no es una regla tan imperativa sino que puede ceder ante razones de eficacia de la justicia» ${ }^{16}$. En el mismo Auto del TSJ valenciano, se añade que un elemento relevante para valorar si conviene o no acumular puede ser el estado en el que se hallen las causas que inicialmente están separadas, pues si una de ellas se encuentra con la instrucción ya cerrada y el objeto procesal ya delimitado, y la otra no, unificar ambos procedimientos puede ser muy antieconómico; dice así:

«El actual estado procesal de la causa del procedimiento del Tribunal del Jurado donde ya se ha procedido a la calificación de los hechos, la duración de dicha instrucción, las diligencias ya practicadas y conclusiones asumidas por el Instructor, aconsejan restringir la valoración sobre la acumulación pretendida a supuestos que pudieran implicar una absoluta, estricta e indisoluble conexión de los hechos. Es decir, a la anteriormente denominada «conexidad necesaria o inevitable» por opuesta a la de «conveniencia». Lo contrario, implicaría afectar seriamente al estado procesal y originar una posible no justificada dilación de dicho procedimiento del Jurado, que sin perjuicio de lo que resulte tras la audiencia preliminar, aparece con un objeto procesal ya conformado. Y ello porque de acceder a la acumulación en estas circunstancias, daría lugar a la reapertura de la instrucción con posible nueva retransformación del procedimiento del Jurado de nuevo al de diligencias previas del procedimiento abreviado (...)».

En alguna otra resolución, precisamente porque las causas inicialmente separadas se encuentran en el mismo estadio procesal -abierta la fase de enjuiciamiento y pendiente la celebración del juicio oral- se estima que lo más adecuado es proceder a la acumulación por conexión, como el Auto de la Audiencia Provincial -en adelante AAP- de Sevilla de 15 de febrero de 2010 (JUR\2011 1232271). En este caso, una vez establecido que concurre uno de los nexos legales de conexión -aquí, el del antiguo art. 17.5 LEC-, el tribunal valora que la acumulación presenta serias ventajas frente a la separación de causas: no sólo que no se generan dilaciones, por la situación temporal ya señalada; sino que además puede facilitarse el acierto en la calificación penal, pues podría tratarse de un delito continuado, al afectar a hechos de la misma naturaleza delictiva; y pueden evitarse repercusiones negativas en caso de ejecución de condenas, puesto que si se condena por separado, podría incurrirse en reincidencia. En cualquier caso, con independencia del resultado favorable a la acumulación por conexión o a la división en la tramitación, lo que se pone de relieve, una vez más, es que el órgano judicial, además de examinar si concurre una causa legal y objetiva de conexión, valora la conveniencia o no del enjuiciamiento conjunto de los distintos hechos punibles.

${ }_{16}$ Otro ejemplo, con las mismas cita, doctrina y conclusión, es el de la Sentencia del TSJ de Islas Canarias de 3 de septiembre de 2014 (ARP\2015\696). 
No obstante las resoluciones anteriores, nos parece que la sentencia más relevante sobre lo que venimos tratando es la STS de 26 de junio de 2012 (RJ $\backslash 2012 \backslash 9057)$, y ello por varios motivos: $1^{\circ}$ ) porque proviene del Tribunal Supremo y no de tribunales inferiores; $2^{\circ}$ ) porque, aunque sin citar su nombre, se hace eco explícitamente de la postura doctrinal del Prof. De la Oliva, que hemos referido y que influyó en la doctrina jurisprudencial posterior; $3^{\circ}$ ) porque se cita y se recoge esta jurisprudencia con claridad, sobre la «conexión necesaria» y la «conexión por razones de conveniencia»; y $4^{\circ}$ ) porque se concluye de un modo muy expresivo que el art. 300 LECr debe interpretarse, no de forma literal sino teleológica, lo que determina que la acumulación de delitos conexos no sea siempre necesaria sino en ocasiones únicamente conveniente, en función de si con ella se cumplen -o no- los fines propios de la institución. Veámoslo:

«Procesalmente el efecto primordial de la conexidad es la necesidad de enjuiciamiento conjunto en una sola causa que impone el art. 300 LECriminal ¿Es una necesidad legal? Los términos del art. 300 parecen imponer esa interpretación: siempre que haya delitos conexos es obligada la tramitación conjunta. Pese a ello resulta de enorme interés la propuesta interpretativa de algunos comentaristas que, apoyándose en razones prácticas y acudiendo a ejemplos de derecho comparado, entienden que la acumulación y tramitación conjunta podrá rechazarse cuando no concurran las razones de fondo que sirven de base al art. 300. Si la necesidad de acumulación va a suponer un retraso injustificado e inútil en la tramitación y no existe peligro de sentencias contradictorias, no será obligada la acumulación al no concurrir las causas teleológicas que fundamentan la institución, pese a existir conexidad. Ésta solo operará a efectos de acumulación cuando se cumplan las finalidades de la institución. La acumulación y enjuiciamiento conjunto sí serán obligados cuando tengan repercusiones en la penalidad (piénsese especialmente en los casos de concurso ideal medial o en los delitos continuados). Por eso se ha llegado a hablar de una conexidad necesaria y una conexidad por razones de conveniencia (vid. STS de 5 de marzo de 1993 y en la misma línea de relativización de la necesidad de enjuiciamiento conjunto, STS 471/1995, de 30 de marzo). Si los arts. 17 y 300 LECriminal responden a razones de agilización de trámites y celeridad, no debe procederse a esa acumulación cuando de la misma solo se van a derivar dilaciones (...).

Por tanto aun cuando se admitiese que estamos ante posibles delitos conexos, ninguna irregularidad relevante se derivaría de ahí, como reconoce el propio legislador al romper la regla combinada de los arts. 300 y 17 LECriminal en diversos casos (formación de piezas separadas, v.gr.) suavizando las consecuencias del art. 300 LECriminal y dejando un cierto margen de discrecionalidad al Juzgador para en atención a las circunstancias concretas y al estado de las causas proceder o no a la acumulación procesal de objetos penales. Sólo cuando puedan derivarse de la decisión sobre acumulación efectos sustantivos no corregibles por la vía del art. 988 de la LECriminal debe evitarse la separación». 
Existen otras sentencias del TS que siguen a esta última, van en la misma línea y son aún previas a la reforma de la LECr de 2015, como la STS de 30 de diciembre de 2013 (RJ\2013\7715), en la que se señala que un elemento que debe valorarse, al ponderar sobre las ventajas o los inconvenientes que presenta la acumulación frente a la separación de causas, es qué consecuencias tendrá esta decisión en el desarrollo de los actos de prueba; porque, claro, si el proceso versa sobre una pluralidad variada de hechos punibles, en los que han intervenido un elevado número de personas, esto puede requerir multitud de actos de prueba, para los que habrá que citar -y dar la oportunidad de intervenir en ellos- a todos los sujetos acusados, y respecto de todas las pruebas que se practiquen, también sobre aquellas que versen sobre hechos que les resulten ajenos. Todo lo cual puede ser muy gravoso para los propios acusados, sus defensas y representantes, además de complicar la tarea de valorar la prueba, si corresponde a un solo tribunal, que deberá presenciar y apreciar una multiplicidad de actos probatorios, dispersos y extendidos a lo largo del tiempo.

En definitiva, pensamos que todo este estado de opinión, doctrinal y jurisprudencial, sirvió de genuino precedente de la reforma legal que se produce en 2015, en virtud de la cual la decisión de enjuiciar conjuntamente varios hechos punibles ya no se producirá de forma automática o necesaria, en todos los casos en que exista conexión delictiva, sino que obedecerá a una valoración del tribunal, en la que tendrá en cuenta los distintos elementos que se han ido apuntando y que, sintéticamente, recoge el nuevo art. 17.1 LECr. Esta valoración se producirá en todos los procesos penales, y ya no sólo en el procedimiento abreviado.

\section{Primeras resoluciones posteriores a la reforma y alcance de la valoración que corresponde al tribunal sobre la acumulación}

El nuevo art. 17.1 LECr deja bastante margen de discrecionalidad al juzgador para decidir si procede acumular o separar el enjuiciamiento de varios delitos conexos. Desde que se aprobó la reforma, se han dictado varias resoluciones en las que se aplica ese precepto, con uno y otro resultado. El examen de algunas de estas resoluciones nos permite constatar cómo se está llevando a la práctica la valoración judicial a la que nos referimos y nos sirve para recapitular cuáles son los elementos en que ha de fijarse el juzgador cuando efectúe dicha valoración.

Ya hemos señalado que, para que el juzgador acuerde la acumulación, en primer lugar debe ponderar que concurran razones positivas de conveniencia, ligadas, según el tenor literal del precepto, con el «esclarecimiento de los hechos» o con la «determinación de las responsabilidades» derivadas de esos hechos. Téngase en cuenta que, desde la perspectiva de estos dos extremos, pueden concurrir razones no sólo de conveniencia sino de necesidad. Es 
decir, en ocasiones puede ser altamente conveniente o incluso necesario que el proceso verse sobre todos los hechos punibles que se hallen estrechamente ligados, bien porque no se sabe dónde empiezan unos y dónde acaban otros, bien porque unos son medios para cometer $\mathrm{u}$ ocultar otros, bien porque han sucedido a la vez al ser actos recíprocos -de un sujeto para con otro y de este segundo para con el primero-, etc. Por tanto, hay determinadas situaciones fácticas en las que, si se quiere alcanzar un grado razonable de certeza respecto de los hechos que han ocurrido, y a fin de poder calificar jurídicamente tales hechos con un mínimo de acierto, e incluso de cara a la aplicación de normas relevantes de penalidad, se hace preciso que el tribunal adopte la acumulación de lo que -desde el principio o después- pueden llegar a ser varios objetos procesales. Entendemos que este tipo de motivos se relacionan con el acierto en el enjuiciamiento y en ellos puede haber más una razón de necesidad que de conveniencia.

Y lo mismo sucede cuando el motivo de la acumulación tiene que ver con la seguridad jurídica, esto es, con evitar que haya duplicidades o pronunciamientos paralelos sobre la misma cuestión (o sobre cuestiones muy similares o muy relacionadas), en los que exista el riesgo de decisiones contradictorias, al menos en algunos de sus elementos. Aquí también estamos ante casos de necesidad -o de muy alta conveniencia- del enjuiciamiento conjunto, más que ante supuestos de mera -o sencilla-conveniencia. En este sentido, resulta ilustrativo el Auto de un Juzgado Central de Instrucción -en adelante JCI- de 30 de diciembre de 2015 (ARP $\backslash 2015 \backslash 1452$ ) en el llamado Caso familia de ex Presidente de la Generalitat de Catalunya, en el que se afirma lo siguiente (la cita es del F.J. 4 y algo extensa pero pensamos que vale la pena):

«Como apuntaba el Fiscal en su requerimiento de inhibición, el fundamento teleológico que subyace bajo el «instrumento jurídico» de la acumulación por conexidad resulta dual, obedeciendo por un lado, a razones de funcionalidad jurídico-procesal -conceptualizadas por nuestro Tribunal Supremo, como supuestos de conexidad contingente o facultativa-, y, por otro, a razones de carácter sustantivo fruto de la necesidad de evitar pronunciamientos paralelos sobre una misma cuestión, corriendo el riesgo de que los mismos pudieran ser contradictorios entre sí -supuestos denominados como «conexidad necesaria».

En este caso, la acumulación por conexidad de los procedimientos judiciales en curso de instrucción resulta no ya sólo funcional, sino asimismo necesaria.

Un simple cotejo entre los hechos objeto de las Diligencias seguidas ante este Juzgado (DP 141/2012) y los de la causa penal seguida en Barcelona (DP 3163/2014), pone claramente de manifiesto la concurrencia en el presente caso de criterios de conexión (art. 17 LECrim), tanto en relación con los inculpados (conexidad subjetiva), como en relación con los hechos 
punibles (conexidad objetiva). Asimismo existe conexión por favorecimiento de la impunidad de otros delitos.

Como se ha indicado anteriormente, los vínculos existentes entre los miembros de la familia; sus pautas comunes de comportamiento; la coordinación de actividades; la asignación de roles; la distribución o reparto de cantidades multimillonarios entre todos ellos en función de los ingresos que recibían en las cuentas bancarias ocultas que mantenían en jurisdicciones extranjeras; y el particular sistema de rendición de cuentas existente para controlar esos repartos de fondos, revelan la existencia de un patrón de comportamiento reiterado durante años, que apuntan elementos básicos de una organización cuyos perfiles definitivos están aún bajo investigación y pendiente de calificar.

A los limitados y estrictos efectos de esta resolución, puede afirmarse que existen indicios de que los miembros de la familia P.F. han venido orquestando durante años una estrategia compartida y coordinada para desarrollar distintos negocios económicos, generar réditos, ocultarlos, y distribuirlos entre todos de acuerdo con criterios establecidos para conseguir el lavado de los activos conseguidos.

Por esta razón, la investigación y enjuiciamiento acerca de la regularidad del origen de la fortuna amasada a lo largo de los años por los miembros de la familia P.F. y las estrategias puestas en marcha para el blanqueo de los capitales generados, no debe ni puede desarrollarse de modo autónomo de la investigación y enjuiciamiento de los hechos que se atribuyen al propio J.P.S. y otros miembros de la familia en cuanto al origen y gestión de los concretos fondos aparecidos en Andorra y respecto de los que mantienen el referido origen hereditario. Y ello porque pudieran derivarse pronunciamientos contradictorios sobre asuntos sustancialmente idénticos, al menos parcialmente, en lo objetivo y lo subjetivo. El conocimiento de estos hechos de manera arbitraria y artificial en procedimientos separados y la consiguiente fragmentación de los hechos, impediría ganar una visión de conjunto sobre los mismos que sitúe a cada miembro de la familia en su justa posición, y vulneraría los principios de indivisibilidad, homogeneidad e identidad fáctica.

Procede por tanto aceptar la competencia de este Juzgado Central para el conocimiento de los hechos a que se refieren las Diligencias Previas número 3163/2014, aceptando la inhibición acordada por el Juzgado de Instrucción número 31 de los de Barcelona».

De esta resolución -y de otras anteriores- se desprende que cuando en la jurisprudencia se habla de «conexión (o conexidad) necesaria» se suele estar aludiendo a la que se basa en motivos de seguridad jurídica o de evitar pronunciamientos paralelos y/o contradictorios ${ }^{17}$. Pero, como decimos, también

${ }^{17}$ Otro ejemplo reciente en el que se decide acumular por un motivo similar es el del Auto del JCI de 15 de febrero de 2016 (JUR\2016\35828): "Con ello se evitará el enjui- 
puede tener ese carácter necesario o «sustantivo» (según otro calificativo del mismo auto anterior), la conexión orientada a que se acierte al enjuiciar, lo cual podemos referir a las tareas consistentes en «esclarecer los hechos» ocurridos, calificarlos debidamente, y «determinar las responsabilidades» que de ellos se pudieran derivar, por emplear algunos de los términos del art. 17.1 LECr. En cualquier caso, conforme a este precepto, el juez que valora si procede o no la acumulación procesal de delitos conexos debe examinar si con ella se favorece positivamente, sea con grado de necesidad o de conveniencia, alguno de los motivos de seguridad jurídica o de acierto en el enjuiciamiento, que se acaban de apuntar.

$\mathrm{Y}$, en segundo lugar, el juzgador debe valorar si el enjuiciamiento conjunto de los delitos supondrá una ventaja o un inconveniente desde la perspectiva de la economía procesal. En el citado precepto, como sabemos, esta valoración se presenta de modo negativo, pues se indica que el tribunal no acordará la acumulación cuando «suponga excesiva complejidad o dilación para el proceso». En particular, como hemos adelantado, es de suponer que la acumulación habrá de denegarse si se calcula que la instrucción conjunta de los delitos conexos superará el tiempo previsto para esta fase procesal con sus plazos y prórrogas- en el art. 324 LECr.

Pero además, sucede que en ocasiones acumular la instrucción y el juicio sobre distintos delitos, más que propiciar un ahorro de tiempo y de actividad jurisdiccional, tiene como resultado que la tramitación procesal de los actos se complica en exceso o se dilata mucho en el tiempo; como ocurre cuando el conjunto de delitos que se unen es elevado, o cuando los sujetos a quienes se atribuyen son muy numerosos. De forma que una de las finalidades que se ha buscado con la reforma de 2015, como se declara en su Exposición de Motivos y señalamos al inicio, es evitar los llamados «macroprocesos». Y así nos encontramos con algunas resoluciones dictadas al poco de aprobarse la reforma que responden a esta finalidad, como el Auto de un Juzgado de Instrucción -en adelante JI- de Sevilla de 21 de diciembre de 2015 (ARP\2015\1450), en el Caso ERES en Andalucía, en el que acuerda la división de la causa en nueve piezas separadas, para facilitar la tramitación de las actuaciones; o el del JCI de 30 diciembre de 2015 (ARP\2016\88), en el Caso Operación Púnica, en el que se confirma la división del procedimiento en doce piezas distintas, con la misma intención. Así, en este último Auto se afirma, gráficamente:

«No hay ruptura de la continencia de la causa, sino un intento de ordenar asequiblemente la marcha procesal de la misma, pues cabe hacerlo a distintas velocidades en función de la materia que se va a ubicar en cada una de las

ciamiento paralelo de ambos procedimientos con repetición de pruebas que pueden ser practicadas en un único procedimiento». 
diferentes piezas, y la intención, conforme permite el art. 762.6 de la LECrim, es evitar dilaciones para pasar al juicio oral cuanto antes a aquellos investigados que por la sencillez de sus hechos punibles podrían ya ser sometidos a juicio oral por tener ya toda la prueba, independiente de la que le afecte a otros; a la vez, no complicar la marcha de la presente instrucción haciendo cientos de notificaciones inútiles e innecesarias en algunos extremos a partes a las que determinadas diligencias no les afectan; no hacer esperar a unos, por lo que finalmente solo atañe a otros, y en definitiva no alargar ni hacer voluminosas instrucciones que lleven como ha ocurrido en casos mediáticamente notorios (juicios sobre hechos ocurridos en Marbella en el pasado) a juicios orales impracticables, de meses y meses, en muchas sesiones en las que el Juez no puede recordar ni asimilar tanta información para poner Sentencias intratables por lo prolongadas y que a las partes imputadas también afectan, pues les generan agendas sorpresivas y les obligan a acudir a sesiones de juicio en las que lo único que hacen es escuchar diligencias que no incumben a sus representados; en definitiva a hacer perder el tiempo y a prolongar la sensación de que la Justicia española es lenta».

Por ello, en este caso se entiende que, aunque la causa haya comenzado siendo única por concurrir nexos de conexión entre los delitos investigados, «por razones de conveniencia, manejabilidad y respeto a otros derechos de otros investigados, se deba proceder a su troceo para ir independizando hechos y circunstancias diferenciables con su oportuna prueba singularizada, y así acelerar enjuiciamientos que eviten dilaciones a aquellos cuya parte de la instrucción ha sido más sencilla y está ya agotada». Y se citan, como apoyo, algunas SSTS de 2015, poco anteriores a la reforma, que insisten en que «el enjuiciamiento fragmentado en piezas separadas es recomendable en aquellos procesos que cuenten con múltiples objetos para acelerar, agilizar y simplificar el enjuiciamiento (...). Que una parte pueda tener que acudir a más de una pieza, es un «precio» procesal que debe pagarse para que a otras cien o más les baste con acudir a una y no tener que estar presente en todas»».

Por tanto, como puede apreciarse, en algunos casos resultará preferible que la causa que empieza como única se divida en varios procesos o en varias piezas separadas, de suerte que cada hecho delictivo -o conjunto de hechosque presente autonomía pueda seguir su propio itinerario procedimental (o lleve su propia «velocidad»), a fin de acotar la instrucción y los actos de que se componga, y después la calificación y los posteriores actos de prueba, a aquello que sea razonable, proporcionado y asumible para las partes afectadas y para los órganos judiciales que hayan de actuar ${ }^{18}$.

${ }^{18}$ Otro ejemplo reciente de división de la causa en varias piezas separadas, por una adecuada celeridad procedimental, es el del Auto de un JI de Valencia de 12 de noviembre de 2015 (JUR\2015\264330), en el Caso Vaersa, en el que se declara: «En definitiva, los hechos que se exponen en este auto y por los que se solicita la formación de pieza separada pueden ser objeto de investigación y, en su caso enjuiciados, con independencia de los 
Y con la misma lógica, de velar por la economía procesal y por un desarrollo razonable de las actuaciones, cuando se pretenda la acumulación de causas que han comenzado por separado, por entender que existen motivos de conexión, habrá que atender a cuál es el estado concreto de cada causa; porque si se encuentran en fases distintas, es posible que no merezca la pena que la más adelantada «espere» a que alcance su situación la más atrasada, no sólo por la dilación que supone este tiempo de espera (de lo que podría proseguir y finalizar por su cuenta), sino también porque la unificación de objetos procesales puede conllevar además que haya que reabrir o volver a realizar algunos trámites ya cerrados.

No obstante, y para terminar, entendemos que estas razones ligadas con la economía procesal, y que pueden propiciar que se separe o que se no acumule el enjuiciamiento de delitos que son conexos, sólo entrarán en juego cuando no exista un motivo de fondo que requiera la acumulación. Es decir, si concurre un motivo de los que propician la llamada conexión «necesaria» $\mathrm{o}$ «sustantiva», relativo a la seguridad jurídica, o a que se pueda calificar como es correcto, deberá decretarse la acumulación; y sólo cuando no haya una razón de genuina necesidad, podrá atenderse - para decidir entre la acumulación o la separación de causas-a las razones de economía procesal, razones que son siempre de conveniencia. Por ello, la conexión fundada únicamente en la economía procesal se denomina -en la jurisprudencia que hemos examinado- como conexión «conveniente» $\mathrm{o}$ «contingente» $\mathrm{o}$ «de mera funcionalidad procesal $»^{19}$.

\section{LOS NEXOS DE CONEXIÓN TRAS LA REFORMA}

Acabamos de ver cómo el nuevo art. 17.1 LECr regula el elemento valorativo -o de apreciación subjetiva- que se requiere para acordar la acumulación procesal de delitos que presentan nexos de conexión. Ahora

que son investigados en las Diligencias Previas 928/14, sin menoscabo ni ruptura de la continencia de la causa, lo que a su vez permitirá simplificar las Diligencias Previas y acelerará notablemente en el tiempo la resolución judicial que en definitiva recaiga sobre tales hechos conforme a la previsión del Legislador contemplada en el precepto transcrito, eludiéndose así dilaciones indebidas».

19 Por razones de espacio, en este trabajo no abordamos los aspectos directamente relacionados con el tratamiento procesal de la conexión, que además presentan muchos interrogantes, pues el silencio legal al respecto es tan amplio como llamativo; y la reforma de 2015 no se ha ocupado en absoluto de ellos. Ahora sólo diremos -con referencia a lo que se acaba de señalar- que la decisión del Juez sobre el enjuiciamiento conjunto de hechos punibles con apariencia de delitos conexos habrá de exteriorizarse y razonarse, por toda la valoración que entraña, y debe poder impugnarse. Dejamos para un futuro trabajo (D.m.) la concreción y el desarrollo de esta y otras importantes cuestiones del tratamiento procesal. 
vamos a estudiar cuáles son los nexos objetivos o vínculos de conexión que recoge la ley, en el nuevo art. 17.2 LECr.

Ya se ha adelantado que el viejo art. 17 contenía cinco casos en los que entendía que los delitos eran conexos. Los cuatro primeros se mantienen en el nuevo art. 17.2, con alguna modificación en el primero de ellos, como veremos enseguida; y el quinto supuesto del precepto antiguo pasa a regularse en el nuevo art. 17.3, aunque sin darle la consideración de una causa de conexión, pero permitiendo que también provoque el enjuiciamiento conjunto de los delitos a los que se refiere -atribuidos al mismo sujeto y con analogía o relación entre sí- siempre que se cumplan ciertas condiciones ${ }^{20}$. Además, en el nuevo art. 17.2 se añaden otros dos supuestos de conexión: Los delitos de favorecimiento real y personal y el blanqueo de capitales respecto del delito antecedente (núm. $5^{\circ}$ ), y Los cometidos por diversas personas cuando se ocasionen lesiones o daños recíprocos (núm. $6^{\circ}$ ).

Veamos en primer lugar los vínculos de conexión que permanecen tras la reforma, y en qué medida se mantienen; para examinar posteriormente los nuevos nexos y su alcance.

\section{Nexos de conexión que se mantienen: las llamadas conexión subjetiva y conexión objetiva}

En algunas resoluciones previas a la reforma se decía que los motivos $1^{\circ}$ y $2^{\circ}$ del viejo art. 17 LECr se referían a la llamada "conexión subjetiva», en tanto que los motivos $3^{\circ}$ y $4^{\circ}$ eran los propios de la «conexión objetiva», y el motivo $5^{\circ}$ regulaba la denominada "conexión mixta». Por ejemplo, así se expresan la Sentencia del TSJ de Andalucía-Granada de 2 de junio de 2015 (JUR $\backslash 2015 \backslash 200333$ ), o el AAP de Sevilla de 15 de febrero de 2010 (JUR $\backslash 2011 \backslash 232271$ ), entre otras. Por lo general, estas resoluciones no

${ }^{20}$ Tampoco trataremos en este estudio el contenido del nuevo art. 17.3 LECr, ni el acierto o desacierto que supone haber excluido el supuesto al que se refiere de los nexos de conexión. Únicamente anotamos que la intención del legislador de 2015 ha sido la que indica en su Exposición de Motivos: «La novedad de la reforma consiste en establecer que la simple analogía o relación entre sí no constituye una causa de conexión y solo se justifica la acumulación cuando, a instancia del Ministerio Fiscal, en su condición de defensor de la legalidad y del interés público, el juez lo considere más conveniente para el esclarecimiento de los hechos y la determinación de las responsabilidades procedentes, salvo que suponga excesiva complejidad o dilación para el proceso, y siempre que con ello no se altere la competencia. Así, además, se evitará el frecuente trasiego de causas entre distintos juzgados a la búsqueda del que deba conocer del asunto por una simple coincidencia de la persona a la que se atribuyen distintos delitos». De nuevo apuntamos aquí nuestro propósito de volver sobre este precepto, ahora no abordado, pero tan relacionado con los apartados 1 y 2 del mismo art. $17 \mathrm{LECr}$, en algún trabajo próximo. 
explicitan la razón de las denominaciones utilizadas, aunque parece claro que aluden al tipo de vínculo existente entre los delitos que se quieren juzgar conjuntamente. Así, en los dos primeros motivos, el nexo guarda relación con los sujetos, pues se trata de delitos cometidos por diferentes personas pero que se han vinculado en su intención criminal. En cambio, en la llamada «conexión objetiva», la ligazón se produce propiamente entre los hechos punibles, pues unos delitos han sido medio o instrumento para perpetrar otros delitos o para procurar su impunidad, con independencia de que se hayan cometido por una sola persona o por varias. En el último motivo, de carácter mixto, que ha dejado de existir como tal motivo de conexión, el enlace entre los delitos que se enjuician se produce tanto en razón de los hechos punibles, que deben presentar analogía o relación entre sí, como en razón del sujeto, al tratarse de un supuesto que comporta unidad de sujeto activo.

\subsection{La llamada conexión subjetiva}

Centrándonos en la llamada «conexión subjetiva», la reforma de 2015 ha modificado el tenor del primero de los nexos legales de conexión. El viejo art. $17.1^{\circ}$ LECr consideraba delitos conexos: «Los cometidos simultáneamente por dos o más personas reunidas, siempre que éstas vengan sujetas a diversos Jueces o Tribunales ordinarios o especiales, o que puedan estarlo por la índole del delito». En tanto que el equivalente nuevo art. 17.2.1 ${ }^{\circ}$ dice de modo más breve: «Los cometidos por dos o más personas reunidas». Por su parte, el segundo motivo de uno y otro precepto (viejo art. $17.2^{\circ}$ y nuevo art. $17.2 .2^{\circ}$ ) tienen idéntico tenor literal, y se consideran delitos conexos: «Los cometidos por dos o más personas en distintos lugares o tiempos si hubiera precedido concierto para ello».

A nuestro juicio, estos dos supuestos de conexión tienen que ser examinados de manera conjunta, pues cabe entender que uno es complementario del otro. En ambos casos, los diversos delitos que pueden tener la consideración de conexos se atribuyen a varios autores. Es decir, junto a la pluralidad delictiva propia de todo caso de conexión ${ }^{21}$, se requiere una pluralidad de sujetos responsables de esas varias infracciones penales; los diversos autores han podido cometer la misma infracción penal, o infracciones diferentes, pero tanto en los casos del núm. $1^{\circ}$ como del núm. $2^{\circ}$ del art. 17.2 LECr hay presente un elemento que vincula subjetivamente a esa pluralidad de autores. En los casos del núm. $1^{\circ}$, el elemento que comporta el nexo es la reunión: las personas que perpetran los delitos susceptibles de enjuiciarse a la vez debían

${ }^{21}$ «Para nosotros, la conexión en el proceso penal tiene como presupuesto fundamental una pluralidad de hechos punibles, una pluralidad de hechos que revisten caracteres de delito» (De la Oliva, La conexión..., 20). 
estar «reunidas» en el momento de su comisión, según el tenor legal. Y en los casos del núm. $2^{\circ}$, el elemento que provoca la ligazón entre los delitos es el concierto: debe haber «precedido concierto», o un acuerdo previo para delinquir, entre las personas a quienes se atribuyen los delitos que pueden considerarse así conexos; personas que en este caso, a diferencia del anterior, no se encontraban reunidas: se hallaban «en distintos lugares o tiempos» cuando llevaron a cabo su actividad criminal.

Como decimos, la redacción del núm. $1^{\circ}$ del nuevo art. 17.2 LECr ha sido modificada respecto de la misma causa de conexión en la regulación anterior. Los puntos de reforma consisten en dos supresiones en la nueva norma. De un lado, en la redacción actual se suprime la referencia a que los delitos cometidos por varias personas reunidas se hayan perpetrado simultáneamente. Esta referencia había sido criticada y matizada por la doctrina, pues ya Gómez Orbaneja señaló que no era preciso que los distintos delitos hubieran tenido exactamente el mismo desarrollo temporal, sino que bastaba con que se hubieran cometido «al mismo tiempo», según el sentido corriente y natural de la expresión, es decir, como realidades que acontecen con unidad temporal; por eso, la «simultaneidad» se podía traducir en ocasiones por «continuidad $)^{22}$.

En nuestra opinión, tal supresión resulta acertada, pues la exigencia de simultaneidad podía confundir; entendemos - con el autor anterior- que lo relevante en estos casos es que los delitos se hayan cometido al mismo tiempo, con unidad temporal: sea el mismo delito perpetrado por varios autores, en cuyo caso la unidad temporal será plena o casi plena, pudiendo haber incluso simultaneidad, o sean diferentes delitos pero cometidos por personas que están reunidas. Es más, consideramos que precisamente el elemento «reunión» ofrece la clave, pues implica de por sí una pluralidad de sujetos que, no sólo se encuentran en un mismo sitio o con conexión espacial, sino también que realizan una actividad a la vez; es decir, dicho término lleva implícito el actuar con «unidad espacial» y con «unidad temporal», aunque una y otra puedan entenderse en un sentido amplio y variado, sin excesivas rigideces. Cuando falta esa «unidad espacial» o esa «unidad temporal» en delitos que se cometen por distintas personas que también están unidas en su intención criminal, pero la unidad viene dada por el acuerdo previo para delinquir, estaremos ante el supuesto núm. $2^{\circ}$ del mismo precepto.

${ }^{22}$ Emilio Gómez Orbaneja, Comentarios a la Ley de Enjuiciamiento Criminal, T. I (Barcelona: Bosch, 1947), 441. Este autor añadía que: «El acento debe ponerse en la continuidad más bien que en la momentaneidad». En el mismo sentido, con cita del anterior, De la Oliva, La conexión..., 39, el cual indicaba: «Bien entendido que simultaneidad quiere decir continuidad». Y se refiere a los dos autores anteriores, Muerza, Las reformas..., 26. 
De otro lado, la redacción del núm. $1^{\circ}$ del nuevo art. 17.2 LECr ha suprimido la condición de que las personas que cometen delitos estando reunidas se hallen sujetas a tribunales distintos, para que pueda entenderse que tales delitos son conexos al amparo del citado precepto. Esta exigencia legal también había sido criticada por la doctrina, y ya en su día De la Oliva abogó por su supresión ${ }^{23}$. Lo relevante para considerar dos o más delitos como conexos es que entre ellos medie un nexo que la ley establezca y que encierre un motivo de necesidad o de conveniencia para la acumulación procesal. Esta necesidad o conveniencia de la acumulación deberá apreciarla el juzgador en cada caso concreto, como hemos visto (en el epígrafe 1), pero todos los supuestos de posibles delitos conexos se han fijado legalmente porque afectan a situaciones en las que resulta previsible que sea aconsejable el enjuiciamiento conjunto. En los casos del art. 17.2.1 $1^{\circ}$, el motivo de conveniencia se cifra en que los delitos se han cometido con «reunión» de sus autores para delinquir. Si los autores de estos delitos conexos determinan la competencia de tribunales distintos, es una consecuencia a la que habrá que atender después para resolver debidamente qué órgano judicial conocerá del único proceso; pero no tiene por qué convertirse en un requisito previo para entender que existe conexión ${ }^{24}$.

La confusión anterior quizá obedecía a un problema que todavía persiste, y es que la regulación de la conexión se sitúa legalmente entre las normas de competencia penal, cuando en realidad es una institución que puede afectar o no a la competencia; es decir, hay delitos conexos cuyo enjuiciamiento se atribuye a diferentes órganos competentes, de suerte que, si se acumula su tramitación, es preciso fijar qué tribunal debe conocer. En cambio, hay otros supuestos de delitos conexos que son competencia del mismo órgano tanto desde el punto de vista objetivo o funcional como territorial. Por ello, entendemos que la conexión debería estar regulada en otra sede, bien con un capítulo propio ${ }^{25}$, bien con las normas que disciplinan el objeto del proceso y su posible pluralidad, o con otras. Pero no podemos entrar ahora a esta cuestión, sino sólo apuntarla.

${ }^{23}$ De la Oliva, La conexión..., 39. En la misma línea se pronunciaba Juan Luis Gómez Colomer, Derecho Jurisdiccional III, Proceso penal (Valencia: Tirant lo Blanch, 2012), 56.

${ }^{24}$ Por eso nos parece criticable, aunque lo digamos sólo de paso, que el art. 17.3 LECr impida, no la conexión pero sí la acumulación de causas, cuando los distintos delitos cometidos por el mismo sujeto y con relación o analogía entre sí conlleven un diferente tribunal competente.

${ }^{25}$ En este sentido, Muerza, Las reformas..., 53; este autor considera que dicho capítulo específico sobre la conexión debería incluir: las reglas o vínculos de conexión; el régimen de jurisdicción y de competencia en caso de conexión delictiva; y el tratamiento procesal de la acumulación en el proceso penal. 
Sobre el vínculo del actual art. 17.2.1 ${ }^{\circ}$ LECr, Muerza pone de relieve que la jurisprudencia de hace unos años lo refería a la comisión simultánea de unos mismos delitos imputables -con el mismo de grado de participación o en grados distintos- a dos o más personas reunidas, «esto es, a los supuestos de co-delincuencia o participación criminal, de modo que cuando falte el previo concierto entre los culpables falta el fundamento de la conexidad, por lo que aquel supuesto se aplicaría sólo en el caso de delito o delitos con los mismos culpables, en el que la conexidad tendría que entrar en juego cuando, por existir fueros personales, los distintos acusados vinieren sometidos a diversos Jueces o Tribunales, lo que perturbaría el enjuiciamiento al romper la continencia de la causa». La cita es de la STS de 5 de marzo de 1993 (RJ 1994\700). Y continuaba así: «Por el contrario, la mera simultaneidad temporal de las acciones de diversas personas, sin nexo subjetivo entre sí, plantea ya más problemas para la determinación de la conexidad, que algunos niegan en tal caso, mientras otros aceptan cuando ocurriendo en el mismo acto y tratándose de acusaciones recíprocas, la resolución que recaiga sobre unos haya de influir sobre los otros» ${ }^{26}$.

La cita de esta interesante sentencia nos sugiere al menos tres comentarios, que vemos precisos para terminar de perfilar lo relativo al supuesto del que tratamos. En primer lugar, con la regulación actual ya no cabe duda de que los distintos delitos cometidos por varias personas reunidas pueden ser conexos, ya determinen el mismo tribunal competente o bien tribunales distintos. En segundo lugar, para los casos de acusaciones recíprocas, en los que han podido producirse dos conductas criminales con unidad de espacio y de tiempo pero claramente sin concierto previo (o sin el elemento de «reunión», al que se refiere el art. 17.2.1 ${ }^{\circ} \mathrm{LECr}$ ), la reforma ha introducido un nuevo supuesto de conexión, en el art. 17.2. $6^{\circ}$, que después estudiaremos. Y en tercer lugar, para nosotros es claro que el supuesto núm. $1^{\circ}$ del art. 17.2 exige que los diversos autores, ya cometan la misma acción criminal entre varios (como se apunta en la sentencia citada), o ya perpetren varios delitos diferentes (caso que entendemos también incluible dentro de este supuesto de conexión), deben actuar unidos en su intención delictiva, de manera que la coincidencia de espacio y de tiempo no puede ser casual sino deliberada; o con los términos de la sentencia citada: debe haber un «previo concierto entre los culpables»y, si no concurre, faltará el fundamento de la conexión. Es cierto que el «concierto» como tal es el elemento que se requiere en el supuesto núm. $2^{\circ}$ del mismo precepto. Pero, como hemos adelantado, pensamos que tanto el elemento reunión exigido en el núm. $1^{\circ}$ como el concierto requerido en el núm. $2^{\circ}$ aluden a que los autores de los distintos delitos se han

${ }^{26}$ Muerza, Las reforma ..., 27; quien cita además otras sentencias relativas al último punto: sobre supuestos de conductas penales concurrentes. 
puesto de acuerdo para delinquir, tienen una misma intencionalidad criminal; sea en el mismo lugar y al mismo tiempo, en los casos del núm. $1^{\circ}$, sea en diferentes lugares o tiempos, en los casos del núm. $2^{027}$.

Si pasamos ya específicamente al supuesto núm. $2^{\circ}$ del art. 17.2 LECr, podemos decir con De la Oliva que en él: «No se requiere unidad de lugar y de tiempo ni tampoco ninguna otra relación entre los diversos delitos que no sea la de una inicial asociación o acuerdo para delinquir. Este acuerdo puede ser expreso o tácito y, desde luego, no tiene por qué comprender los detalles de cada uno de los actos criminales. En definitiva, lo que se intenta alcanzar estableciendo esta causa de conexión es la más fácil represión de la delincuencia asociada ${ }^{28}$.

Como ejemplo de aplicación de este supuesto de conexión, en el que se aprecia la finalidad de perseguir formas de delincuencia asociada, puede verse el ATS de 2 de febrero de 2012 (JUR\2012\53308), relativo a una trama organizada de empresas, que «ofrecían a ciudadanos extranjeros ofertas de trabajo a cambio de una contraprestación económica para que éstos regularizaran su situación en España si estaban ilegales, para renovar el permiso de residencia o bien solicitar autorización de residencia y trabajo a sus familiares que se encontraban en sus países de origen. La mayoría de las víctimas o perjudicados declaran que no han trabajado para ninguna de las empresas implicadas y han obtenido el permiso de trabajo por cantidades que oscilan entre los 100 y los 1300 euros. Estas ofertas se utilizaban, a su vez, para conseguir la autorización de residencia (...)». En este caso había tres empresas implicadas, dos de ellas domiciliadas en Orihuela: una de la que eran socios fundadores L.A. y M.D, siendo esta última la administradora única, y una segunda de la que L.A. era el socio único; más una tercera, con domicilio en Murcia, de la que M.D. era el único socio. Por tanto, la relación entre los sujetos es clara, dada la composición de las empresas; y también está acreditado que estas empresas llevaban a cabo su actividad de forma asociada. Por ello, aunque comenzaron diligencias contra las dos personas mencionadas por separado, unas en Orihuela y otras en Murcia, finalmente se acumularon: «pues los hechos descritos pueden ser constitutivos de falsedad en documento, delito contra los derechos de los trabajadores y delito de asociación, delitos conexos del art. 17.2 LECrim ${ }^{29}$.

${ }^{27}$ De «una intencionalidad criminal única de diversos sujetos» habla De la Oliva, $L a$ conexión ..., 39, para referirse al «concierto», pero con relación únicamente a los casos del núm. $2^{\circ}$. Es más, para los casos del núm. $1^{\circ}$ entiende que no debe haber «previa solidaridad de propósito» entre las diversas personas que actúan reunidas. Y sigue en esto a Gómez Orbaneja, Comentarios..., 442.

${ }^{28}$ De la Oliva, La conexión..., 40.

29 Otro ejemplo claro de personas que se asocian, formando una organización para delinquir, en este caso dedicada a realizar matrimonios de conveniencia, lo ofrece el Auto del TSJ de Cataluña de 24 de octubre de 2013 (JUR\2014\18370). 
De manera que en estos supuestos la clave es que se acredite suficientemente ante el tribunal que la pluralidad de personas que cometen una pluralidad de delitos actúan de manera asociada, mediando un acuerdo entre ellas; acuerdo que puede adoptar formas o manifestaciones diversas, pero en todo caso ha de ser previo a las conductas delictivas y debe quedar claro que éstas responden a un propósito delictivo común. Como señala Muerza: «si no se acredita la existencia de un acuerdo previo, no podrá estimarse este vínculo de conexión ${ }^{30}$. Y cita como ejemplo el ATS de 1 de octubre de 2008 (JUR\2008\319836), en el que se afirma:

«(...) de lo actuado no se desprenden elementos que permitan fundar la conexidad delictiva que en su caso determinaría la obligación de instruir en un solo procedimiento los hechos que dieron lugar a la formación de las Diligencias, conforme al artículo 17.2, porque el concierto previo que exige dicha norma en delitos cometidos por dos o más personas en distintos lugares o tiempos, no se acredita en este caso, pues existen varios imputados por hechos diferenciados y sin que entre ellos exista más relación, en principio, que tener la misma nacionalidad, y así existiendo diversos lugares de comisión y constando que se siguen diferentes procedimientos por cada uno de los ciudadanos chinos implicados y que en su mayoría se encuentran en fase de calificación o habiéndose ya dictado auto de apertura del juicio oral, todo ello lleva a declarar la competencia del Juzgado (...)».

Es más fácil apreciar el concierto, claro está, cuando los delitos que se cometen por los distintos sujetos tienen la misma naturaleza, pero aún en estos casos debe concurrir algún elemento objetivo del que quepa deducir el concierto.

Así, por ejemplo -y para cerrar apartado- en el caso del AAP Cantabria de 23 de julio de 2014 (JUR \2015\288774), referente a un delito de tráfico ilegal de ciudadanos extranjeros, en el que se procedía «a reagrupar a supuestos parientes mediante la presentación de documentación falsa en las oficinas de extranjería»; se abrieron dos causas distintas en diferentes juzgados de Santander, cada una contra un sujeto diferente, pero se acumularon al entender que eran conexas, ya que «no sólo nos encontramos ante la investigación de conductas similares por parte de ambos denunciados, sino ante la existencia de un punto de conexión entre ambos del que cabe deducir la presencia del concierto delictivo sobre el que bascula la conexidad, cual es que los imputados facilitaron ante la administración para la reagrupación de sus supuestos parientes, el mismo domicilio... lo que constituye un criterio determinante de la competencia al suponer un nexo de enlace objetivo en la comisión de dichos delitos».

${ }^{30}$ Muerza, Las reformas..., 28-29. 


\subsection{La llamada conexión objetiva o instrumental}

Las siguientes causas de conexión no han sufrido modificación alguna en la reforma de 2015. Son los motivos $3^{\circ}$ y $4^{\circ}$ tanto del viejo art. 17 como del nuevo art. 17.2 LECr y, conforme a estos preceptos, se considerarán delitos conexos, respectivamente: «Los cometidos como medio para perpetrar otros o facilitar su ejecución», y «Los cometidos para procurar la impunidad de otros delitos». Así, se trata de supuestos en los que existe una pluralidad de delitos, como en todo caso de conexión, que han sido cometidos por el mismo sujeto activo o por sujetos distintos, ya que las normas citadas no distinguen y caben ambas posibilidades, y en los que el nexo entre los diferentes delitos consiste en que unos son medios o instrumentos de los otros; de manera que siempre hay al menos un delito-medio y un delito-fin, y el delitomedio sirve para cometer el delito-fin (o para que sea más fácil cometerlo), o bien para evitar la persecución o el castigo del delito-fin. Por tanto, el enlace se produce propiamente entre los hechos punibles y con esta relación de medio a fin, por lo que este tipo de conexión se califica en algunas sentencias ya citadas como objetiva, o también la podemos denominar conexión medial o instrumental $l^{31}$.

Un ejemplo típico de la conexión del núm. $3^{\circ}$ del actual art. 17.2 LECr es el de la falsedad documental que se comete con el fin de perpetrar una estafa, como ocurre, p.ej., si se manipula un DNI para hacerse pasar por otra persona, con la intención de pedir un extracto bancario y posteriormente retirar dinero en efectivo de su cuenta: así, en el Auto del TSJ de Andalucía-Granada de 14 de mayo de 2014 (JUR\2015\9411); o también sirve de ejemplo el robo de vehículos que se realiza con la finalidad de perpetrar otros robos en establecimientos por medio del sistema conocido como «alunizaje»: como aparece en el AAP de Madrid de 5 de mayo de 2010 (JUR\2010\240414). Y una muestra de casos del núm. $4^{\circ}$ nos la ofrece el AAP de Madrid de 29 de diciembre de 2013 (JUR\2014\298891), relativo a la falsedad documental en que se incurre, mediante la alteración de la fecha de una sentencia y de la correspondiente notificación al procurador, a fin de ocultar el comportamiento de un abogado en un proceso contencioso-administrativo, que fue calificado de deslealtad profesional.

En los ejemplos anteriores se aprecia cómo, en estos supuestos, siempre hay dos (o más) hechos punibles, con sustantividad propia, y que podrían enjuiciarse por separado, pues se puede cometer una falsedad documental que no esté ordenada a perpetrar otro delito, como la estafa, o a ocultar otro comportamiento delictivo, como la deslealtad profesional; del mismo modo

31 Algunos autores se refieren a ella como conexión teleológica, ver De la Oliva, $L a$ conexión..., 41, nota 36 . 
que el robo de unos coches es un delito per se y separable del robo de establecimientos que se efectúa estrellando dichos coches contra ellos. Pero también se observa que unos delitos son claramente instrumentales de otros, y que los autores han llevado a cabo los llamados delitos-medios (la falsedad documental o el robo de vehículos) con el fin primordial de ejecutar los respectivos delitos-fines (la estafa o los «alunizajes»), o bien para evadir su persecución (en el caso de la falsificación de fechas y la deslealtad profesional). Esta pre-ordenación de unos delitos a otros comporta importantes consecuencias, tanto procesales como penales. Desde el punto de vista procesal, puede ser muy aconsejable que el delito-medio se enjuicie junto con el delito-fin, pues aunque se trate-como decimos-de delitos distintos y distinguibles, en el caso concreto forman una cierta unidad, ya que el delito medio no se busca en sí mismo, sólo se comete como «paso» para lograr el resultado que realmente quiere alcanzarse, que es el del delito-fin; la intencionalidad que prima y que está presente desde el inicio es la del delito-fin. Y precisamente por la cierta unidad que forman los delitos, en tanto que uno se subordina al otro, pero sin llegar a confundirse o a integrar un solo tipo penal, desde el punto de vista sustantivo, los casos de «conexión instrumental» pueden conllevar la aplicación de una regla penológica específica, cual es la del art. 77.3 CP.

Así es. En este punto conviene recordar que los arts. 73 y ss. CP contienen reglas especiales para la aplicación de las penas en los casos de concurso de delitos. El art. $73 \mathrm{CP}$ se refiere a cuando una misma persona ha sido condenada por varios delitos, disponiendo que deberá cumplir las penas de todos ellos si es posible simultáneamente (porque sean de distinta naturaleza, p.ej., una inhabilitación y una multa); y si no se puede a la vez (porque sean de la misma naturaleza, p.ej., la privación de libertad), se cumplirán de forma sucesiva, según el art. $75 \mathrm{CP}$. Para el cumplimiento sucesivo de las distintas penas, el art. 76.1 CP determina unos límites, de manera que la suma de todas ellas «no podrá exceder del triple del tiempo por el que se le imponga la más grave», estableciendo a su vez un tope máximo, que será: de veinte años, para la generalidad de casos; o bien de veinticinco o treinta años, para los casos en que uno de los delitos conlleve una pena de prisión de hasta veinte años o de más de veinte años, respectivamente; o el límite será de cuarenta años, cuando haya dos o más delitos con penas superiores a veinte años o se trate de delitos de terrorismo. El apartado 2 del mismo art. $76 \mathrm{CP}$ señala que estos límites se aplicarán aunque las penas se hayan impuesto en procesos distintos, siempre que sea por hechos que ocurrieron antes de la fecha en que fueron enjuiciados los primeros hechos, y que unos y otros hechos punibles hubieran podido acumularse: se entiende que por concurrir un nexo de conexión del art. 17 LECr.

$\mathrm{El}$ art. $77 \mathrm{CP}$ se presenta como una excepción a lo dispuesto en los arts. 75 y $76 \mathrm{CP}$. Y si estos dos preceptos se refieren a los llamados concursos reales de delitos, en los que un mismo autor comete dos o más delitos diferentes 
y debe cumplir acumuladamente la pena de todos ellos, el art. $77 \mathrm{CP}$ contempla dos supuestos distintos, calificables de concurso ideal de delitos, el primero, y de concurso medial, el segundo, para los que prevé unas reglas específicas de penalidad ${ }^{32}$.

El concurso ideal de delitos conlleva que «un solo hecho constituya dos o más delitos» (art. 77.1 CP), de manera que con un mismo hecho se atacan varios bienes jurídicos y se hace precisa la aplicación de diferentes normas penales, para que así toda la conducta realizada pueda «desvalorarse» íntegramente, en términos de la doctrina penal; como sucede, p.ej., si una persona es detenida por un policía y responde con un puñetazo que rompe la nariz al agente: con el mismo hecho se efectúa un ataque a su integridad física y un atentado a la autoridad ${ }^{33}$. Para estos casos, el art. 77.2 CP establece que no se sumarán las penas de los distintos delitos que concurren sino que se aplicará únicamente la pena de la infracción más grave, en su mitad superior (siempre que esto sea menos gravoso que la suma, claro está); y ello se debe a que se ha realizado «un solo hecho».

En cambio, en el concurso medial, se llevan a cabo dos o más hechos, que suponen varios delitos, de forma que «uno de ellos sea medio necesario para cometer el otro» (art. 77.1 CP). Para estos casos, la regla penológica es que «se impondrá una pena superior a la que habría correspondido, en el caso concreto, por la infracción más grave, y que no podrá exceder de la suma de las penas concretas que hubieran sido impuestas separadamente por cada uno de los delitos» (art. 77.3 CP). Por tanto, aquí la penalidad es más severa que en el concurso ideal de delitos (aunque sólo desde la reforma del Código Penal de 2015, porque antes era la misma para los dos casos), lo que se explica porque en el concurso medial el condenado ha efectuado dos hechos diferentes y no sólo uno. Pero a la vez es más benigna que en un genuino concurso real de delitos, pues no se suman las penas de los delitos que

${ }^{32}$ Sobre la teoría de los concursos de delitos, hemos seguido la explicación y algunos ejemplos contenidos en Margarita Martínez Escamilla, María Martín Lorenzo y Margarita Valle Mariscal de Gante, Derecho Penal. Introducción. Teoría jurídica del delito (Madrid: Universidad Complutense de Madrid, 2012), 385 y ss.

${ }_{33}$ A diferencia de lo que sucede en los concursos de normas, en los que sólo se aplica un tipo penal, pese a que aparentemente habría que aplicar varios al afectar el hecho a distintos bienes jurídicos, pero resulta que una sola norma aglutina todo el desvalor que presenta el hecho cometido. P.ej., si una persona ataca con una navaja a otra y le quita la cartera, existe un ataque al patrimonio de la víctima y a la vez se atenta contra su libertad personal; pero no se trata de sumar al delito de hurto uno de coacciones, por cuanto existe un tipo consistente en el robo con violencia o intimidación. Como señalan Martínez Escamilla et al., Derecho Penal..., 387: «En gran medida, si acudimos a una o varias normas penales para la calificación de unos hechos va a depender de la concreta configuración de los tipos penales y de cómo los interpretemos». 
constituyen los dos hechos punibles, y la razón de esta excepción radica en que estos dos hechos punibles aparecen con una fuerte ligazón, formando una cierta unidad, en tanto que uno se comete como medio, y además como medio necesario -dice aquí la ley- para cometer el otro delito ${ }^{34}$.

P.ej., si el administrador de una empresa falsifica la firma del presidente en varios cheques y los ingresa en su cuenta, realiza dos hechos distintos y separables, la falsificación y el ingreso, que determinarán la aplicación de dos tipos penales diferentes - de falsedad documental y de apropiación indebida- puesto que se lesionan dos bienes jurídicos distintos; pero estas dos conductas se castigarán en la forma indicada, dado que la primera se ha concebido y realizado justo para perpetrar la segunda.

En consecuencia, el concurso medial es un tipo específico de concurso real de delitos, con una regla de penalidad excepcional, más benévola y justificada en la subordinación e intensa relación de los dos hechos punibles que lo componen. Pero por fuerte que sea esta relación, no desemboca en unidad, sino que sigue existiendo una pluralidad delictiva. Y la pluralidad de delitos enlazados es lo propio de todo caso de conexión. De hecho, cabe apreciar que todo concurso medial de delitos supone una conexión delictiva del art. 17.2.3 $3^{\circ} \mathrm{LECr}$, a la que hemos denominado conexión objetiva, instrumental e incluso medial, pues concurrirán dos delitos, en este caso cometidos por el mismo sujeto, con una relación entre ellos de medio a fin. Sin embargo, no sucede lo mismo a la inversa, pues no toda conexión objetiva o instrumental determinará un concurso medial de delitos. Y ello principalmente por dos razones. La primera, porque el concurso medial, como todo concurso de delitos, requiere idéntico sujeto activo de los hechos punibles que aparecen ligados; y el art. 17.2.3 ${ }^{\circ}$ LECr permitiría una conexión de esta clase entre delitos que tuvieran diferentes sujetos responsables, puesto que el nexo se establece primariamente entre los hechos punibles. Esto no es lo que más sucede en la práctica, pero puede pensarse en teoría.

$\mathrm{Y}$ el segundo motivo por el que puede haber una conexión objetiva o instrumental sin que exista concurso medial de delitos tiene que ver con que el art. 77.1 CP exige que el delito-medio sea «medio necesario para cometer el otro delito»; en tanto que, según el citado precepto de la LECr, para que

${ }^{34}$ De la Oliva (La conexión..., 201-202) señala que la regla penal referida se entiende mejor si se atiende a que encierra un supuesto de conexión, y citando a Carnelutti afirma que la conexión «ocupa un puesto intermedio entre la unidad y la pluralidad», «de manera que un estrechamiento de la conexión puede, contra lo que parece en principio, llegar a producir incluso una desaparición de la pluralidad (y con ella, de la misma conexión), apareciendo en su lugar una unidad compleja o, al menos, induciendo a un tratamiento unitario en algunos aspectos de lo que todavía continúe siendo, en otros, un fenómeno de pluralidad». 
exista conexión es suficiente con que haya un delito que sea «medio para perpetrar otros», sin referencia a la necesidad del medio, bastando incluso que el primer delito meramente facilite la ejecución del segundo ${ }^{35}$.

Ahora bien, ¿qué implica que un delito haya de ser medio necesario para cometer otro delito? O con otros términos, ¿a qué clase de necesidad se está aludiendo? Parece que no puede ser una necesidad absoluta y general, que se halle presente en todos los casos, pues si siempre es preciso llevar a cabo un determinado hecho punible para poder cometer un delito, esto indica que el primer hecho punible debería integrarse en el tipo penal del delito pretendido, formando, en su caso, un concurso de normas. De manera que la necesidad debe advertirse con relación al caso concreto de que se trate. Como señala la STS de 9 marzo de 2007 (RJ $\backslash 2007 \backslash 802)$ :

«La dificultad para determinar la existencia, o no, del concurso medial estriba en dar un concreto contenido a la expresión de «medio necesario» que exige el presupuesto del concurso. En principio esa relación hay que examinarla desde el caso concreto exigiendo que la necesidad exista objetivamente, sin que baste con que el sujeto crea que se da esa necesidad. Ahora bien tampoco cabe exigir una necesidad absoluta, pues esa exigencia chocaría con el concurso de Leyes en la medida en que esa exigencia supondría la concurrencia de dos Leyes en aplicación simultánea».

Así, como primer punto, la necesidad del delito-medio debe presentarse como tal en el caso concreto; pero además, debe ser objetiva, es decir, debe responder a parámetros objetivos que el delito-medio es una vía apta y precisa para lograr el resultado que se busca con el delito-fin. Y como tercer elemento, esta necesidad de cometer un delito para perpetrar otro ha de estar presente en la intención inicial del autor, que concibe la comisión del primero como parte imprescindible del plan para poder llevar a cabo el segundo. A este respecto, nos parecen luminosos la explicación y el ejemplo de la STS de 31 de marzo de 2014 (RJ $2014 \backslash 2152)$ :

«Los comentaristas del siglo XIX nos enseñan que en su origen con la previsión de este tipo específico de concurso -medial- el legislador pretendía dar respuesta unitaria a lo que se presentaba como un plan único del autor. Parecía primar el criterio subjetivo como parámetro interpretativo de la «necesidad», lo que arroja resultados equivalentes a estimar que la necesidad ha de medirse «en concreto»; es decir no como necesidad «absoluta», sino como necesidad «relativa» en atención a la secuencia delictiva efectivamente llevada a cabo. El problema tiene algo de aporético: no caben dogmas, sino solo algunas orientaciones.

${ }^{35}$ Además, en ningún caso la conexión instrumental del núm. $4^{\circ}$ del mismo art. 17.2 LECr (delitos cometidos para procurar la impunidad de otros delitos) supondrá un concurso medial de delitos. 
En muchos casos esta Sala ha negado el concurso medial entre la tenencia de explosivos y los delitos cometidos efectivamente con ellos. Lo recuerda el Fiscal. Pero en esa decisión influía de forma muy determinante que la tenencia de explosivos era más estable o permanente y no focalizada para una acción concreta.

En este supuesto la fabricación del explosivo llevada a cabo por el condenado aparece ligada de forma puntual y exclusiva al propósito de agredir a la víctima. Está dirigida a esa finalidad: no tiene otra distinta, ni se fabrican otros explosivos más allá de los «necesarios» para llevar a cabo su objetivo de atentar contra la integridad de la persona frente a la que albergaba ese rencor. La tenencia es «efímera»: lo que requería el plan propuesto. En estas condiciones podemos hablar de la relación de medio a fin que describe el art. $77 \mathrm{CP}$ y castigar como un concurso medial».

Por tanto, si dos conductas punibles realizadas por un mismo sujeto no están ligadas en la intención primitiva del autor - de que una sea medio para cometer la otra-, sino que simplemente se aprovecha la ocasión de que se ha cometido la primera para perpetrar la segunda, podrá haber concurso real de delitos, castigado según lo dispuesto en los arts. 75 y $76 \mathrm{CP}$, pero no habrá concurso medial, al que le sea aplicable la penalidad prevista en el art. 77.3 CP. Y ocurre que, en un caso así, quizá tampoco exista la conexión del art. 17.2.3 LECr, pues aunque este precepto no exija explícitamente que los delitos medio $\mathrm{y}$ fin se hallen ligados en la intencionalidad originaria del autor, pensamos que entenderlo así es lo más acorde con la finalidad de la norma (aunque en puridad no pueden excluirse de este supuesto de conexión los casos en que el delitomedio no estaba previsto y ha de cometerse de forma sobrevenida).

En conclusión sobre el extremo que estamos tratando: cabe pensar que hay casos de conexión objetiva o instrumental que no constituyen un concurso medial de delitos, como sucede cuando cambia el sujeto activo de los delitos conexos, o si la relación de medio a fin entre dichos delitos no se presenta como necesaria -en los términos examinados- sino que resulta ser más «tenue» o sólo consistente en que un delito «facilita» la ejecución de otro. Pero nótese que, en la práctica, cuando se entiende aplicable el art. 17.2.3 ${ }^{\circ} \mathrm{LECr}$ y se acuerda la acumulación del enjuiciamiento de los delitos conexos por este motivo, lo más frecuente es que se trate de delitos atribuidos al mismo o a los mismos sujetos, $\mathrm{y}$, además, el delito instrumental suele aparecer como medio necesario para perpetrar el delito-fin, tanto objetivamente como desde el punto de vista del sujeto que lo comete. Por ello, aunque en el foro los conceptos de conexión instrumental y de concurso medial de delitos se presentan muchas veces unidos, no han de confundirse, pues en teoría pueden y deben deslindarse.

Con todo, no se olvide que, para que haya conexión delictiva, es preciso que exista una pluralidad de delitos. Y en ocasiones puede ser muy complicado determinar si el conjunto de actos que el autor ha realizado integra una 
sola conducta criminal, a la que se le aplica un único tipo penal, porque forma un concurso de normas (o porque se trata de un delito continuado del art. 64 $\mathrm{CP}$ ), o si por el contrario los distintos actos conforman varias infracciones penales, por atentar contra diferentes bienes jurídicos, constituyendo un concurso de delitos (que será real o medial, si se han cometido varios hechos punibles, o meramente ideal, cuando se entienda que sólo hubo un hecho punible pero que conlleva la aplicación de diferentes tipos penales, como se ha visto). Para que haya conexión debe haber varios delitos, y estos pueden formar o no un concurso, en función de si se cumplen las reglas de los concursos delictivos; en la conexión objetiva o instrumental, si hay concurso, éste será medial, cuando un delito sea medio necesario para cometer otro, y habrá concurso real en el resto de supuestos ${ }^{36}$.

\section{Los nuevos nexos de conexión}

Como se ha adelantado, la reforma de 2015 introduce dos motivos nuevos de conexión, que ya se habían previsto en el Borrador de Código Procesal Penal elaborado en 2013 (y que no llegó a iniciar siquiera su andadura parlamentaria); en este caso, el precepto que recogía los nexos de conexión era el art. 24 de dicho Código, y la redacción y números de estos dos nuevos nexos eran los mismos que finalmente han quedado en el reformado art. 17 LECr, que considera delitos conexos, en su apartado 2, de un lado, «Los delitos de favorecimiento real y personal y el blanqueo de capitales respecto al delito antecedente» (núm. 5. ${ }^{\circ}$ ), y de otro lado, «Los cometidos por diversas personas cuando se ocasionen lesiones o daños recíprocos» (núm. $\left.6 .^{\circ}\right)^{37}$. Veámoslos.

${ }^{36}$ Muerza (Las reformas..., 31-36) se hace eco de la dificultad de determinar si se está ante un único delito o ante varios, y para ilustrarla expone y comenta con detalle el interesante caso de la STS de 25 de marzo de 2014 (RJ $2014 \backslash 2539$ ), relativa a un delito de falsificación de documento mercantil, en concurso medial con un delito de estafa procesal. Y también se refiere a la STS de 23 de abril de 2014 (RJ\2014\2197), sobre un concurso medial del delito de falsificación de tarjetas de crédito con el de estafa cometida por su uso posterior.

${ }^{37}$ En el art. 24 del Código Procesal Penal referido, se añadía un núm. $7^{\circ}$, que daba la consideración de delitos conexos también a «Los hechos que constituyan delito continua$d o »$. No es momento de comentar la conveniencia de incluir o no este supuesto entre los nexos de conexión, pero al menos queremos dejar apuntado que el pre-legislador anterior se planteó incluirlo. Al igual que sucedió en el Anteproyecto de Ley Procesal Penal de 2011, que, entre los motivos de conexión dispuestos en su art. 21, recogía, junto a las infracciones recíprocas, aquéllas que podían entenderse constitutivas de un delito continuado ( $\sin$ incluir, en cambio, los delitos de favorecimiento y el blanqueo de capitales respecto del delito antecedente). 


\subsection{Los delitos de favorecimiento real y personal y el blanqueo de capitales respecto del delito antecedente}

Así, en el nexo del art. 17.2.5 ${ }^{\circ} \mathrm{LECr}$, se pretende unir el enjuiciamiento de un delito origen o antecedente con un delito subsiguiente o consecuente; y se refiere a los casos en que el delito consecuente es el de favorecimiento real o personal, o el blanqueo de capitales.

Los delitos de favorecimiento real y personal se identifican con las modalidades del delito de encubrimiento recogidas, respectivamente, en los números $2^{\circ}$ y $3^{\circ}$ del art. $451 \mathrm{CP}$. En ambos casos se trata de una conducta de quien conoce la comisión de un delito del que no es responsable -ni como autor ni como cómplice- $\mathrm{y}$, con posterioridad a su ejecución, interviene: en el favorecimiento real, actuando sobre el cuerpo del delito origen, o sobre sus efectos o instrumentos, de manera que los oculta o altera o inutiliza, con el fin de impedir que se descubran; y en el favorecimiento personal, el autor realiza actos de ayuda a los presuntos responsables del delito antecedente para que eludan la investigación que puede abrirse por este delito, o para que se sustraigan de su busca y captura, siempre que se cumpla alguna de las circunstancias mencionadas en el referido art. $451.3^{\circ} \mathrm{CP}$ : que se trate de uno de los delitos, especialmente graves, mencionados en él (como los de traición, o contra la Corona, o contra la Comunidad Internacional, o de terrorismo, etc. $)^{38}$, o bien que el favorecedor haya obrado con abuso de funciones públicas. Por tanto, en los delitos de favorecimiento, entendemos que la conducta constitutiva de este delito consecuente radica en esconder la perpetración de un delito antecedente, o a sus posibles responsables, de suerte que se evite la persecución penal, como delitos contra la Administración de Justicia que son. El nuevo núm. $5^{\circ}$ del art. 17.2 LECr determina que el delito antecedente y el consecuente, en estos casos, han de considerarse conexos y deben enjuiciarse acumuladamente (de cumplirse también, claro está, los requisitos del art. 17.1 LECr, ya estudiados).

Ahora bien, nótese que las modalidades delictivas de los arts. $451.2^{\circ} \mathrm{y}$ $451.3^{\circ} \mathrm{CP}$ están claramente orientadas a «procurar la impunidad de otros delitos», por lo que bien cabe entender que la nueva conexión recién referida, entre los delitos de favorecimiento y el delito antecedente cuya impunidad se favorece, no es sino un caso concreto y específico del motivo de conexión dispuesto en el art. 17.2.4 $\mathrm{LECr}$.

${ }^{38}$ El tenor literal del art. $451.3^{\circ}$, a) CP es el siguiente: «Que el hecho encubierto sea constitutivo de traición, homicidio del Rey o de la Reina o de cualquiera de sus ascendientes o descendientes, de la Reina consorte o del consorte de la Reina, del Regente o de algún miembro de la Regencia, o del Príncipe o de la Princesa de Asturias, genocidio, delito de lesa humanidad, delito contra las personas y bienes protegidos en caso de conficto armado, rebelión, terrorismo, homicidio, piratería, trata de seres humanos o tráfico ilegal de órganos». 
Como consecuencia de lo afirmado, si entendemos que los delitos de favorecimiento real y personal sólo se disponen en los números $2^{\circ}$ y $3^{\circ} \mathrm{del}$ art. $451 \mathrm{CP}$ respectivamente, no cabría entender como delito conexo con su antecedente la modalidad de encubrimiento recogida en el núm. $1^{\circ}$ del mismo precepto penal, conocida como delito de «auxilio complementario», y consistente en auxiliar a los responsables de un delito previo para que se beneficien del provecho, producto o precio que se derive de dicho delito, sin ánimo de lucro por parte de quien ayuda. La única manera de que este delito tuviera encaje en el art. 17.2.5 $\mathrm{LECr}$ es que se considerara una forma de favorecimiento personal; lo que no nos parece descabellado. Y otro tanto sucede con el delito de receptación del art. $298 \mathrm{CP}$, que tampoco se menciona expresamente en el art. 17.2.5 ${ }^{\circ} \mathrm{LECr}$, a diferencia del blanqueo de capitales, delito con el que integra el mismo capítulo del CP. La receptación implica ánimo de lucro en su autor, que será quien haya tenido noticia de un delito de carácter patrimonial, en el que no haya participado como autor o cómplice, y respecto del que «ayude a los responsables a aprovecharse de los efectos del mismo», o bien «reciba, adquiera u oculte tales efectos». De manera que, junto a una ventaja económica propia, se tiene la intención de procurar una ganancia ajena, o conlleva una actuación de ocultamiento de los efectos del delito antecedente. Y cuando ocurre esto último, cabe pensar que hay favorecimiento real; de modo parecido a que, cuando se ayuda a los responsables del delito origen, puede considerarse como una suerte de favorecimiento personal. Visto así, la receptación tendría cabida en el art. 17.2.5 ${ }^{\circ} \mathrm{LECr}$, y podría tenerse como un delito conexo con el delito del que sea consecuente.

La clave de lo anterior, por tanto, está en determinar cuál ha de ser el contenido y las notas que definen los «delitos de favorecimiento real y personal». Si se entiende que la nota esencial de estos delitos es que concurra un acto de «ocultamiento» de un delito anterior, evitando que éste se descubra o que sus responsables sean perseguidos, en tal caso los delitos de favorecimiento quedarán encerrados en los $451.2^{\circ}$ y $451.3^{\circ} \mathrm{CP}$, y los delitos de los arts. $451.1^{\circ} \mathrm{y}$ 298 CP no podrán considerarse conexos con sus delitos antecedentes; a menos que sea por otro motivo de conexión, como el concierto previo, del art. 17.2.2 $2^{\circ}$ LECr. En cambio, si se acoge un concepto más amplio de favorecimiento, que albergue actuaciones por las que se facilita que los autores de un delito previo obtengan un provecho o beneficio del mismo, entonces, los delitos de «auxilio complementario» y de receptación tendrán pleno encaje en el art. 17.2.5 ${ }^{\circ}$ LECr. En nuestra opinión, esta cuestión debe ser resuelta por la doctrina penalista ${ }^{39}$. Desde una perspectiva procesal, sólo añadiremos

${ }^{39}$ Muerza (Las reformas...,56-57), siguiendo a Justo Fernando Balmaceda Quirós, Delitos conexos y subsiguientes. Un estudio de la subsecuencia delictiva (Barcelona: 
que no encontramos motivos que justifiquen que los delitos de favorecimiento real y personal -aun en sentido estricto- junto con el blanqueo de capitales sí sean considerados conexos con los delitos que los preceden, y que no suceda lo mismo con los delitos de «auxilio complementario» y de receptación. En estos dos últimos casos también existe una clara ligazón entre el delito origen y el delito consecuente, que puede hacer conveniente, si resulta posible, que se enjuicien de forma conjunta.

De lo que no hay duda es de la inclusión específica del blanqueo de capitales entre los delitos conexos - con sus delitos antecedentes- en el art. 17.2.5 LECr. El blanqueo de capitales se regula en los arts. 301-304 CP, y se considera autor de este delito, en su tipo básico, al que «adquiera, posea, utilice, convierta, o transmita bienes, sabiendo que éstos tienen su origen en una actividad delictiva, cometida por él o por cualquiera tercera persona, o realice cualquier otro acto para ocultar o encubrir su origen ilicito, o para ayudar a la persona que haya participado en la infracción o infracciones a eludir las consecuencias legales de sus actos» (art. $301.1 \mathrm{CP}$ ). El blanqueo de capitales admite así distintas formas de cometerse, y algunas de ellas conllevan un favorecimiento real o personal, como puede apreciarse. También se observa que presenta varias diferencias con el delito de receptación, que cabe resumir en las siguientes: $1^{\circ}$ ) en el blanqueo de capitales no se requiere expresamente ánimo de lucro en el autor (cosa que sí sucede en la receptación); $2^{\circ}$ ) la actividad delictiva anterior al blanqueo de capitales ha podido ser de cualquier clase, aunque hay ciertos tipos de delitos previos que conllevan una mayor penalidad en el delito consecuente (en tanto que la receptación tiene siempre como antecedente un delito contra el patrimonio o contra el orden socioeconómico); y $3^{\circ}$ ) el delito antecedente puede haber sido cometido por el mismo autor del

Atelier, 2014), es partidario de hacer una interpretación amplia de qué ha entenderse por «delitos de favorecimiento real y personal» a los efectos del art. 17.2.5 $5^{\circ} \mathrm{LECr}$, que incluiría, de un lado, «situaciones en las que se puede contemplar la influencia de unos hechos que se producen antes, simultáneamente o con posterioridad, respecto de otros. Tal es el caso de los actos preparatorios punibles, la tentativa y la participación delictiva (inducción, cooperación necesaria y complicidad)». Y de otro lado, lo que el autor al que sigue denomina «subsecuencia delictiva», referida a los supuestos en que un hecho delictivo requiere para su configuración de un delito que debe acontecer previamente: «Es una conducta adhesiva "post-ejecutiva" configurada como un delito posterior, nuevo (diferente y autónomo), pero a la vez dependiente respecto del previo»; y cita numerosos ejemplos, como el tráfico de órganos, el descubrimiento y revelación de secretos, diversas clases de estafas o de fraudes, etc.

A nuestro juicio, tal interpretación resulta desmesurada y nos parece forzar enormemente los límites del concepto de «favorecimiento», que por mucho que se amplíen nunca pueden contener una categoría tan amplia y relativa a delitos tan distintos como la que se acaba de apuntar, de subsecuencia delictiva. 
blanqueo de capitales o por otro autor distinto (y en la receptación el autor del delito anterior ha de ser necesariamente otro sujeto).

Sea como fuere, la última reforma legal del art. 17 LECr ha querido que, en lo posible, el blanqueo de capitales se enjuicie conjuntamente con el delito que lo preceda. Esto a veces no será factible, porque se desconozca cuál es la actividad delictiva anterior o quiénes son sus autores. Y aun cuando resulte posible, en ocasiones quizá no sea lo más conveniente, si con ello se dificulta la investigación y el esclarecimiento de lo ocurrido, en especial cuando los hechos sean relativos a complicadas tramas de delincuencia económica. De hecho, en jurisprudencia anterior a la reforma, como la STS de 28 de abril de 2004 (RJ 2004 13038), entre otras, se alertaba de que: «en aquellos asuntos que afectan de manera grave a la economía nacional, se debe valorar, en cada caso concreto, la posibilidad de tratamiento autónomo y separado de aquellas operaciones que, por su configuración, permiten un enjuiciamiento por separado». No obstante, la valoración a la que se refiere esta resolución no sólo es posible sino que es obligada con la nueva norma, pues, como bien sabemos, el art. 17.1 LECr exige al juzgador que valore si la eventual acumulación de causas -sobre delitos unidos con vínculos legales de conexión- va a facilitar o a dificultar la determinación de los hechos punibles y de sus responsables; y en función de esto, se ordenará la tramitación conjunta o separada de las causas.

Como ejemplo en el que se opta por acumular, precisamente para garantizar un mayor acierto en la investigación así como un ahorro de actuaciones procesales, sirva el Auto del Juzgado de Instrucción de Barcelona de 4 de diciembre de 2015 (ARP $\backslash 2015 \backslash 1477$ ), dictado al poco de aprobarse la reforma, y tanto con apoyo en la regulación anterior -en ese momento aún vigente- como en el nuevo art. 17 LECr. Dice así: «En el presente caso, es evidente que concurre esa conexidad delictiva que hace necesario unificar ambos procedimientos por cuanto la investigación del origen de los fondos depositados en Andorra por los querellados no puede hacerse de forma independiente al resto de los fondos operados por D. J. P. F. Cierto es que los querellados han manifestado que su capital proviene de la herencia de su abuelo, pero aun admitiendo la improbable realidad de tal legado, el importe del mismo ascendería, según palabras del Sr. P. S., a no más de 140 millones de pesetas (unos 841.000 euros) y sin embargo, los ocho beneficiarios pudieron llegar a percibir varios años después, cuando menos, un millón de euros cada uno, atendiendo al saldo de mayor valor que ostentaba la querellada M. P. Si tan voluminoso incremento hay que atribuirlo a la gestión de D. J. P. F., como él mismo reconoció al admitir que recibió en su momento unos tres millones de euros que consiguió rentabilizar muy satisfactoriamente, y el Juzgado Central de Instrucción núm. 5 sospecha de la legalidad de esa actuación, se infiere que los querellados se habrían podido favorecer con ello, y cabría decir que más que la herencia de su abuelo, lo que en realidad habrían recibido son los beneficios de las 
dudosas actividades económicas realizadas por el mayor de los hermanos. Ello obliga a la acumulación de ambas investigaciones, coincidiendo con el Ministerio Fiscal en que ello permitirá un análisis conjunto de la actuación de la familia P. y en todo caso, facilitará poder avanzar en la instrucción de la presente causa que, ante la falta de colaboración de las autoridades judiciales andorranas, había llegado a un punto muerto».

\subsection{Los delitos de lesiones o daños recíprocos}

El sexto y último número de los motivos de conexión dispuestos en el art. 17.2 LECr es el de los delitos «cometidos por diversas personas cuando se ocasionen lesiones o daños recíprocos». Este nexo de conexión también estaba previsto en los Anteproyectos de Ley Procesal Penal de 2011 y de Código Procesal Penal de 2013, y venía siendo reclamado por la doctrina desde hace tiempo ${ }^{40}$.

$\mathrm{Si}$ en una situación, una persona agrede a otra, y esta segunda reacciona atacando al agresor, causándose daños el uno al otro, parece muy razonable que las dos posibles infracciones - de A sobre B y de B sobre A-se enjuicien en una misma causa, toda vez que provienen de un mismo conjunto fáctico. Si se dividen las causas, se corre el riesgo de que difieran los hechos probados en cada una y, consecuentemente, las sentencias puedan ser contradictorias. A la vez, dado que antes no existía un amparo legal expreso para la tramitación conjunta de estas infracciones recíprocas -sin que, por supuesto, sirviese el nexo del núm. $1^{\circ}$ del antiguo art. 17 y actual art. 17.2 LECr, de ser delitos cometidos por dos o más personas reunidas-, y como no se concebía que quien actuase procesalmente como parte pasiva pudiera ser parte acusadora en el mismo proceso, el resultado fue que durante bastante tiempo hubo una jurisprudencia contradictoria, en la que a veces se permitía la acumulación en tales casos y a veces no. Esta situación de incertidumbre vino a ser resuelta por el Acuerdo del TS de 27 de noviembre de 1998, recogido por primera vez en la STS de 10 de diciembre de 1998 (RJ $\backslash 1998 \backslash 10336$ ), así como en muchas otras posteriores. Así, por ejemplo, en la STS de 28 de abril de 2006 (RJ $\backslash 2006 \backslash 5371$ ), en la que se declara:

«Y hay que recordar que la posibilidad de actuar en la doble condición de acusado y acusador en los supuestos de lesiones mutuas, ha sido objeto de posiciones controvertidas. La necesaria clarificación de la postura de esta sala, en aras de lograr la unificación en la aplicación del Derecho que constituye uno de sus cometidos esenciales, determinó que este tema se sometiera a Sala General, lo que tuvo lugar el 27 de noviembre de 1998, adoptándose el siguiente acuerdo: «Con carácter excepcional, cabe la posibilidad de

${ }^{40}$ Así, Gómez Orbaneja, Comentarios..., 442; y De la Oliva, La conexión..., 48. 
que una misma persona asuma la doble condición de acusador y acusado, en un proceso en el que se enjuician acciones distintas, enmarcados en un mismo suceso, cuando, por su relación entre sí, el enjuiciamiento separado, de cada una de las acciones que ostentan como acusados y perjudicados, produjese la división de la continencia de la causa, con riesgo de sentencias contradictorias, y siempre que así lo exija la salvaguarda del derecho de defensa y de la tutela judicial efectiva» (S 10-12-1998, núm. 1178/1998). En el caso actual concurren una íntima relación entre las mutuas lesiones por lo que el enjuiciamiento separado produciría la división de la continencia de la causa, con riesgo de sentencias contradictorias»».

Por tanto, al establecerse legalmente este supuesto de conexión se recoge lo que venía aplicándose por nuestros tribunales desde hace unos años. Algún ejemplo de sentencia en la que ya se invoca el art. 17.2.6 $6^{\circ} \mathrm{LECr}$ es la SAP de Madrid de 5 de octubre de 2016 (ARP $\backslash 2016 \backslash 1218$ ), relativa a un supuesto «de infracciones conexas enjuiciables en un mismo proceso, al proceder de unos mismos hechos - una pelea multitudinaria y violenta, como es el caso-»; o también, y con esto terminamos, la SAP de León de 11 de noviembre de 2016 (JUR\2016\265959), sobre una agresión mutua, en la que se condena a ambos agresores-agredidos, y se señala:

«En efecto, si se tiene en cuenta que los hechos enjuiciados: las presuntas y reciprocas agresiones entre Arcadio y Bernabé han de considerarse infracciones conexas, según el_artículo 17.2.6º de la Ley de Enjuiciamiento Criminal, que considera delitos conexos los cometidos por diversas personas cuando se ocasionen lesiones o daños recíprocos, no se ve la necesidad, como no sea desde una posición estrictamente formalista, de que, iniciada la fase preprocesal con el atestado a que dio lugar la denuncia inicial presentada por Arcadio, no se ve la necesidad, decimos, de que debiera Bernabé comparecer, aparte, formulando su propia denuncia siendo así que una y otra, la de Arcadio y Bernabé, estaban llamadas a ser tramitadas en un solo y mismo procedimiento... de modo que no se ve inconveniente en que Bernabé aprovechara ese proceso ya comenzado a instancia de Arcadio para hacer patente su voluntad de que se conociera en el mismo de los hechos, presuntamente delictivos de los que se consideraba víctima, siendo eso mismo lo que ha sucedido, como resulta del acta de 19 de enero de 2016, en la que Bernabé compareció ratificando su declaración en el atestado, que el mismo consideraba como una denuncia, y reclamando por los daños y perjuicios sufridos».

\section{CONCLUSIONES}

1. El principal punto de reforma de las normas de conexión ha sido evitar la aplicación automática de los criterios legales que permiten entender que dos o más delitos son conexos $\mathrm{y}$, consecuentemente, deben ser 
instruidos y enjuiciados en un mismo proceso. El tenor del anterior y derogado art. 300 LECr parecía imponer de manera necesaria que, siempre que se estuviese en presencia de hechos punibles que la ley considerase como delitos conexos, su enjuiciamiento debería ser conjunto.

A partir de la reforma, para que proceda tal acumulación, no sólo será preciso contar con el elemento objetivo de estar ante hechos que revistan la apariencia de delitos conexos, sino que además se requiere un elemento subjetivo o valorativo, con una doble perspectiva: por un lado, se requiere que el órgano judicial aprecie positivamente que la investigación y el enjuiciamiento conjunto de los hechos va a resultar conveniente para su esclarecimiento y para la determinación de las responsabilidades que procedan; y por otro lado, debe valorarse si dicha acumulación procesal no tendrá como consecuencia negativa que el proceso se complique o se ralentice de manera excesiva. Por tanto, cabe afirmar que la nueva regulación ha supuesto un paso de la necesidad a la conveniencia del enjuiciamiento conjunto de los delitos conexos.

2. Ya alguna doctrina preconizó hace décadas que, pese a la redacción del antiguo art. 300 LECr, debía dejarse a la ponderación del juzgador en cada caso concreto la decisión de unir o separar las causas sobre delitos conexos, atendiendo a si con la acumulación se cumplían o no los fines propios de esta institución, que no son otros, en esencia, que velar por la seguridad jurídica de evitar pronunciamientos contradictorios, o alcanzar una mayor economía procesal. Cuando no se lograsen estos fines, o no estuviera en juego el acierto en la calificación, o la aplicación de relevantes normas de penalidad, podría decretarse la separación de causas por delitos que presentasen nexos de conexión. La visión descrita influyó en la introducción de una norma legal, entre las que regulan el procedimiento abreviado, según la cual «podrá acordar el Juez la formación de las piezas separadas que resulten convenientes para simplificar y activar el procedimiento». Con apoyo en esta base legal se fue generando una jurisprudencia cada vez más favorable a que el juzgador habría de valorar -no sólo en el procedimiento abreviado sino en todos los procesos- si convenía o no la tramitación conjunta de los delitos conexos. Y todo este estado de opinión, doctrinal y jurisprudencial, pensamos que ha servido de genuino precedente de la reforma legal producida en 2015.

3. El alcance de la valoración que ha de efectuar el tribunal para decidir si acuerda o no la acumulación procesal de delitos conexos, según los parámetros que cabe deducir de la jurisprudencia (anterior y posterior a la reforma), pasa por examinar: en primer término, si existen 
motivos para una «conexidad necesaria» o sustantiva, y que se relacionan tanto con el fin de evitar sentencias contradictorias, como con el acierto a la hora de calificar los hechos, o de poder acreditarlos como ciertos, o de aplicar con corrección las normas referentes a su penalidad; y en segundo lugar, no habiendo razones como las que se acaban de mencionar, se podrá atender a si concurren motivos para una «conexidad conveniente» o de mera funcionalidad procesal, que se cifra en la economía procesal o la celeridad o simplificación de las actuaciones.

4. En cuanto al elemento objetivo, la reforma de 2015 ha mantenido cuatro de los cinco nexos existentes en la regulación anterior, y ha sumado dos nexos nuevos. Los nexos continúan ubicándose en el art. 17 LECr, en concreto en su segundo apartado; el primer apartado queda reservado para el elemento valorativo al que nos hemos referido; y el tercero y último para el supuesto que ha dejado de ser motivo de conexión, relativo a los delitos que se atribuyen a un mismo sujeto y que presentan analogía o relación entre sí, pero respecto de los que se permite su enjuiciamiento conjunto siempre que se cumplan ciertas condiciones.

5. Los dos primeros motivos del art. 17.2 LECr regulan lo que puede denominarse "conexión subjetiva», y son complementarios uno del otro. En ambos casos, los diversos delitos que cabe considerar conexos se atribuyen a varios autores. Esta pluralidad de sujetos responsables han podido cometer la misma infracción penal, o infracciones diferentes, pero tanto en los supuestos del núm. $1^{\circ}$ como del núm. $2^{\circ}$ hay un elemento que vincula subjetivamente a la pluralidad de autores. En el núm. $1^{\circ}$, dicho elemento es la «reunión»: las personas que perpetran los delitos susceptibles de enjuiciarse a la vez debían estar «reunidas» en el momento de su comisión, según el tenor legal; y esta reunión implica unidad espacial y unidad temporal, aunque sean consideradas en sentido amplio. En los casos del núm. $2^{\circ}$, el elemento que provoca la ligazón entre los delitos es el «concierto» previo para delinquir entre las personas a quienes se atribuyen tales delitos; estas personas no se encontraban reunidas, sino que se hallaban «en distintos lugares o tiempos» cuando llevaron a cabo su actividad criminal.

Con la reforma, se ha suprimido la condición de que las personas que cometen delitos estando reunidas se hallen sujetas a tribunales distintos, para que pueda entenderse que esos delitos son conexos. Y es que lo relevante para considerar dos o más delitos como conexos es que entre ellos medie un nexo que la ley establezca y que encierre un motivo de necesidad o de conveniencia para la acumulación procesal. Si los autores de estos delitos conexos determinan la competencia de 
tribunales distintos, es una consecuencia a la que habrá que atender después, para resolver debidamente qué órgano judicial conocerá del único proceso; pero no tiene por qué convertirse en un requisito previo para entender que existe conexión.

Para nosotros es claro que el núm. $1^{\circ}$ del art. 17.2 LECr exige que los diversos autores, ya cometan la misma acción criminal entre varios, o ya perpetren varios delitos diferentes, deben actuar unidos en su intención delictiva, de manera que la coincidencia de espacio y de tiempo no puede ser casual sino deliberada, es decir, debe haber un concierto entre los culpables, que, de no concurrir, faltará el fundamento de la conexión. Es cierto que el «concierto» como tal es el elemento que se requiere en el núm. $2^{\circ}$ del mismo precepto; pero, como decimos, pensamos que tanto el elemento «reunión» (del núm. $1^{\circ}$ ) como el «concierto» (del núm. $2^{\circ}$ ) aluden a que los autores de los distintos delitos se han puesto de acuerdo para delinquir, tienen una misma intencionalidad criminal; sea en el mismo lugar y al mismo tiempo, sea en diferentes lugares o tiempos.

6. Los supuestos del núm. $3^{\circ}$ y del núm. $4^{\circ}$ del art. 17.2 LEC son calificables de «conexión objetiva o instrumental». En ellos existe una pluralidad de delitos, como en todo caso de conexión, que han sido cometidos por el mismo sujeto activo o por sujetos distintos, ya que las normas no distinguen y cabrían ambas posibilidades, y en los que el nexo entre los diferentes delitos consiste en que unos son medios o instrumentos de los otros: siempre hay al menos un delito-medio y un delito-fin, y el delito-medio sirve para cometer el delito-fin (o para que sea más fácil cometerlo), o bien para evitar su persecución o castigo. Esta pre-ordenación de unos delitos a otros comporta importantes consecuencias, tanto procesales como penales. Desde el punto de vista procesal, puede ser muy aconsejable que el delito-medio se enjuicie junto con el delito-fin, pues aunque se trate de delitos distintos y distinguibles, en el caso concreto forman una cierta unidad, pues el delito medio no se busca en sí mismo, sólo se comete como "paso» para lograr el resultado que realmente quiere alcanzarse, que es el del delito-fin.

Precisamente por la cierta unidad que forman los delitos, en tanto que uno se subordina al otro, pero sin llegar a confundirse o a integrar un solo tipo penal, desde el punto de vista sustantivo, los casos de «conexión instrumental» pueden conllevar la aplicación de una regla penológica específica: la relativa a los concursos mediales de delitos. En estos concursos se llevan a cabo dos o más hechos, que suponen varios delitos, de forma que «uno de ellos sea medio necesario para cometer el otro» (art. 77.1 CP). Y la regla penológica es que se impondrá la 
pena superior a la que habría correspondido, en el caso concreto, por la infracción más grave (art. 77.3 CP). Esta regla es más benigna que la del concurso real de delitos, pues no se suman las penas de los delitos que constituyen los dos hechos punibles, y la razón radica en que estos dos hechos punibles aparecen con una fuerte ligazón, ya que uno se comete como medio, y como medio necesario, para cometer el otro delito.

Ahora bien, cabe apreciar que todo concurso medial de delitos supone una conexión delictiva del art. 17.2.3 ${ }^{\circ} \mathrm{LECr}$, pues concurrirán dos delitos, en este caso cometidos por el mismo sujeto, con una relación entre ellos de medio a fin. Sin embargo, no sucede lo mismo a la inversa, pues no toda conexión objetiva o instrumental determinará un concurso medial de delitos. Y ello principalmente por dos razones. La primera, porque el concurso medial, como todo concurso de delitos, requiere idéntico sujeto activo de los hechos punibles que aparecen ligados, y el art. 17.2.3 ${ }^{\circ} \mathrm{LECr}$ permite una conexión de esta clase entre delitos que tengan diferentes sujetos responsables; por tanto, si cambia el sujeto activo de los delitos conexos, no habrá concurso medial. $\mathrm{Y}$ el segundo motivo tiene que ver con que el art. 77.1 CP, que exige que el delito-medio sea medio «necesario» para cometer el otro delito, mientras que la conexión no requiere tal necesidad del medio, bastando incluso que el primer delito meramente facilite la ejecución del segundo. Por ello, aunque en el foro los conceptos de conexión instrumental y de concurso medial de delitos se presentan muchas veces unidos, no han de confundirse, pues en teoría pueden y deben deslindarse.

7. Los nuevos nexos de conexión se regulan en los números $5^{\circ}$ y $6^{\circ}$ del mismo art. 17.2 LECr. El vínculo del art. 17.2.5 $5^{\circ}$ pretende unir el enjuiciamiento de un delito origen o antecedente con un delito subsiguiente o consecuente; y se refiere a los casos en que el delito consecuente es el de favorecimiento real o personal, o el blanqueo de capitales.

Los delitos de favorecimiento real y personal se suelen identificar con las modalidades del delito de encubrimiento recogidas, respectivamente, en los números $2^{\circ}$ y $3^{\circ}$ del art. $451 \mathrm{CP}$. Aunque de entenderlo así, no cabría considerar como delito conexo con su antecedente la modalidad de encubrimiento recogida en el núm. $1^{\circ}$ del mismo precepto, conocida como delito de «auxilio complementario». Y otro tanto sucede con el delito de receptación del art. $298 \mathrm{CP}$, que tampoco se menciona expresamente en el art. 17.2.5 $5^{\circ}$ LECr, a diferencia del blanqueo de capitales, con el que integra el mismo capítulo del CP. La clave, por tanto, está en determinar cuál ha de ser el contenido y las 
notas que definen los «delitos de favorecimiento real y personal»; en nuestra opinión, esta cuestión debe ser resuelta por la doctrina penalista. Desde una perspectiva procesal, sólo diremos que no encontramos motivos que justifiquen que los delitos de los arts. $451.2^{\circ}$ y $3^{\circ} \mathrm{CP}$ junto con el blanqueo de capitales sí sean considerados conexos con los delitos que los preceden, y que no suceda lo mismo con los delitos de los arts. $451.1^{\circ}$ y $298 \mathrm{CP}$, puesto en estos dos últimos casos también existe una clara ligazón entre el delito origen y el consecuente, que puede hacer conveniente, si resulta posible, el enjuiciamiento conjunto.

En cuanto a la acumulación del blanqueo de capitales con el delito que lo preceda, debe considerarse que a veces no será factible, porque se desconozca cuál es la actividad delictiva anterior o quiénes son sus autores; y aun cuando resulte posible, en ocasiones quizá no sea lo más conveniente, si con ello se dificulta la investigación y el esclarecimiento de lo ocurrido, en especial cuando los hechos sean relativos a complicadas tramas de delincuencia económica, como se reconoció en jurisprudencia anterior a la reforma.

8. Por último, los delitos de lesiones o daños recíprocos son considerados conexos en el sexto y último número del art. 17.2 LECr. Este nexo venía siendo reclamado por la doctrina desde hace tiempo, pues parece muy razonable que tales infracciones se enjuicien en una misma causa, toda vez que provienen de un mismo conjunto fáctico, y si se dividen las causas, se corre el riesgo de que las sentencias sean contradictorias. A la vez, como no existía un amparo legal expreso para la tramitación conjunta de las infracciones recíprocas, y no se concebía que quien actuase procesalmente como parte pasiva pudiera ser parte acusadora en el mismo proceso, el resultado fue que durante bastante tiempo hubo una jurisprudencia contradictoria, en la que a veces se permitía la acumulación en esos casos y a veces no. Esta situación vino a ser resuelta por el Acuerdo del TS de 27 de noviembre de 1998, asumido en posteriores sentencias; por lo que, al establecerse legalmente este supuesto de conexión, se recoge lo que venía aplicándose ya por nuestros tribunales.

\section{BIBLIOGRAFIA}

Aguilera Morales, Marien, «La agilización de la justicia penal en el proyecto de reforma de la Ley de Enjuiciamiento Criminal (O «de cuando el oro parece»), Diario La Ley, $\mathrm{n}^{\circ} 8551$ (2015): 5.

Balmaceda Quirós, Justo Fernando, Delitos conexos y subsiguientes. Un estudio de la subsecuencia delictiva (Barcelona: Atelier, 2014). 
De la Oliva Santos, Andrés, La conexión en el proceso penal (Pamplona: EUNSA, 1972).

Gómez Colomer, Juan Luis, Derecho Jurisdiccional III, Proceso penal (Valencia: Tirant lo Blanch, 2012).

Gómez Orbaneja, Emilio, Comentarios a la Ley de Enjuiciamiento Criminal, T. I (Barcelona: Bosch, 1947).

Martínez Escamilla, Margarita, Martín Lorenzo, María y Valle Mariscal de Gante, Margarita, Derecho Penal. Introducción. Teoría jurídica del delito (Madrid: Universidad Complutense de Madrid, 2012).

Muerza Esparza, Julio, Las reformas procesales penales de 2015 (Cizur Menor: Aranzadi, 2015). 